\title{
El primer período de desempleo de técnicos y técnicos superiores
}

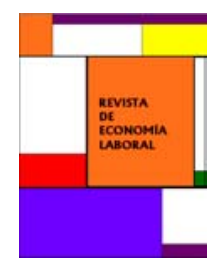

\author{
Sara M. González-Betancor¹, C. Delia Dávila Quintana, \\ José A. Gil Jurado \\ Universidad de Las Palmas de Gran Canaria
}

Recibido el 26 de septiembre de 2003; aceptado el 12 de mayo de 2004

Received 26 September 2003; accepted 12 May 2004

\section{Resumen:}

El presente trabajo estudia la longitud del primer episodio de desempleo, entre los titulados de Ciclos Formativos de la isla de Gran Canaria, a partir de una muestra de 2054 egresados que obtuvieron su titulación entre los cursos académicos 1997/98 a 1999/2000. Mediante la estimación de modelos de duración no paramétricos se identifican los factores que afectan a la duración del primer período de desempleo de técnicos y técnicos superiores, para, seguidamente, obtener estimaciones más precisas mediante la utilización de modelos de distribución de supervivencia. De esta manera detectamos diferencias significativas en función del género así como de la Familia Profesional elegida.

Palabras clave: modelos de duración, desempleo, formación profesional Clasificación JEL: J64, C41

\begin{abstract}
:
This paper studies the duration of the first unemployment of vocational training graduates who obtained their degree at the island of Gran Canaria. The sample consists of 2054 graduates who finished their studies between 1997/98 and 1999/2000. Using nonparametric estimation methods we obtain a set of plausible variables that influence on the unemployment spell we are studying. From this point on, we get more precise estimations using parametric methods for the estimation of survivor functions. By this way, we observe significant differences between genders and between the different specializations of vocational training
\end{abstract}

Keywords: duration models, unemployment, vocational education.

JEL Classification: J64, C41

1 Autora para correspondencia:sgonzalez@dmc.ulpgc.es. Los autores agradecen las sugerencias y comentarios al manuscrito recibidos de un evaluador anónimo.

(C) Revista de Economía Laboral 


\section{Introducción}

En el presente trabajo realizamos una aproximación al proceso de búsqueda de empleo por parte de los titulados de Formación Profesional Específica de la isla de Gran Canaria. Dicha aproximación, a través del análisis de la duración del primer período de desempleo de técnicos y técnicos superiores, tiene la finalidad de detectar qué factores influyen en la mayor o menor duración de esta primera etapa de la trayectoria ocupacional de estos titulados.

Nuestro interés se centra en la situación en la que el titulado, que ya ha finalizado su período de formación técnico-profesional, toma la decisión de incorporarse al mercado de trabajo. Es a partir de este momento, cuando nos cuestionamos qué factores pueden ser los que influyen en la duración de su primer período de desempleo. Es decir, qué factores provocan que, una vez que el titulado ha decidido comenzar a buscar empleo, su proceso de búsqueda se prolongue durante más o menos tiempo.

El problema del desajuste entre la demanda y la oferta de trabajo, y sobre todo desde el punto de vista cualitativo más que desde el cuantitativo, ha sido objeto de interés de numerosas investigaciones, realizadas tanto dentro, como fuera de España. Las políticas activas de mercado de trabajo se han revelado asimismo como un arma fundamental para los gobiernos en su intento por combatir el desempleo y la escasez de mano de obra cualificada. Ya en 1990 la OCDE y la Comisión Europea ${ }^{2}$ señalaban como objetivo de las políticas activas el desarrollo de las cualificaciones profesionales que mejor se adaptasen a los trabajos disponibles. Algunas de estas medidas aumentaron la flexibilidad y la variedad de opciones. Y ello en aras de reducir el déficit de personal cualificado demandado por las empresas y de integrar los objetivos con los de las políticas de enseñanza y formación. El éxito de estas políticas ha sido dispar, si bien la creación de vías de tránsito o pasarelas entre la enseñanza general y la formación profesional o entre ésta y la universidad ha tenido buenos resultados. Así, según recoge la OCDE en su informe de 2002 sobre Perspectivas del Empleo, la existencia de un sistema dual en el que los jóvenes transitan entre la escuela y el aprendizaje con programas como los National Training Awards o los New Apprenticeships se ha revelado como una vía eficaz para el logro de un empleo ${ }^{3}$. Por el contrario, los mercados más liberalizados, en los que hay escasa coordinación entre

2 OCDE (1990) "Políticas de mercado de trabajo para la década de los noventa" y Comisión Europea (1990) "El empleo en Europa").

${ }^{3}$ Más del 90\% de los nuevos aprendices de 1999 conservaron ese empleo o encontró otro antes de mitad de 2000 . 
los empresarios a escala sectorial, han realizado escasos esfuerzos en el fomento del sistema de aprendizaje (Bowers et al, 1999).

La mayor parte de los estudios acerca de la duración del desempleo, lejos de centrarse exclusivamente en el primer período de desempleo tras la finalización de una titulación determinada, tienen como variable objetivo la duración del período de desempleo en cualquier instante de la vida laboral (Theeuwes, 1989; Han y Hausman, 1990; Ahn y Ugidos-Olazábal, 1995; Stancanelli, 1998; Melkersson, 1999; Bratberg y Nilsen, 2000; Lázaro-Pardo et al., 2000; Petrongolo, 2001; Bover et al., 2002; Gámez-Amián y García-Pérez, 2002 y Kettunen, 2002; Alba-Ramírez y Álvarez-Llorente, 2004). Devine y Kiefer (1993) recopilaron, dos años después de la publicación de su libro sobre la teoría de la búsqueda de empleo, los resultados empíricos más relevantes en relación con la búsqueda de empleo.

Aún así, nos encontramos con algunas investigaciones recientes, que centran su análisis en aquel período de desempleo que se produce nada más abandonar el sistema educativo, como puede ser el caso del trabajo de Biggeri et al. (2001). Estos investigadores, realizan su estudio utilizando los datos de una encuesta de oportunidades laborales realizada por el Instituto Nacional de Estadística Italiano a los titulados universitarios graduados en 1992. A partir de la misma, analizan las transiciones desde el sistema educativo hacia el mercado laboral, centrándose en el tiempo necesario hasta obtener el primer empleo. De esta manera, encuentran evidencias de la importancia de la finalización de los estudios en el tiempo establecido, de la necesidad de obtención de notas altas en el caso de las mujeres (y no de los hombres), así como de poseer experiencia laboral previa, para reducir la duración de dicho período de desempleo.

En el ámbito de España también encontramos estudios que centran parte de su análisis en el primer período de desempleo tras el abandono del sistema educativo. Este es el caso de la tesis doctoral realizada por Gil-Jurado (1998), quien analiza la duración del primer período de desempleo de los titulados universitarios de la Universidad de Las Palmas de Gran Canaria entre 1988 y 1996; la realizada por SalasVelasco (2000), quien analiza lo propio para los titulados universitarios de la Universidad de Granada registrados en Colegios Profesionales; así como la de Aguilar-Ramos (2001), que considera la duración de dicho período de desempleo para dos cohortes diferentes de jóvenes de la Encuesta Sociodemográfica de 1991.

De la misma manera, otro estudio reciente en el ámbito de España, es el que realizan Congregado-Ramírez y García-Pérez (2002) utilizando datos del módulo de transición de la educación inicial al mercado laboral, 
El primer periodo desempleo de técnicos y técnicos superiores

que incorpora la EPA en el segundo trimestre de 2000. Estos investigadores estiman modelos de duración para el período de transición entre la educación y el mercado laboral de los individuos entre 16 y 35 años, con la finalidad de indagar en los factores económicos e individuales que facilitan/dificultan dicha transición en Andalucía. De esta manera, entre otros factores, encuentran evidencias de la influencia del nivel educativo, tanto propio como de sus progenitores, así como de la situación profesional de los últimos, sobre la tasa de salida del desempleo. De hecho, comprueban cómo, cuando sus progenitores están ocupados y su nivel de estudios es alto, así como cuando su propio nivel educativo es alto, la duración en el primer período de desempleo de los individuos es menor. Igualmente observan que los especializados en disciplinas de técnicas y biomédicas tienen una mayor probabilidad de salida del desempleo, que los especializados en arte y humanidades.

En cualquier caso, con la excepción del análisis de Gil-Jurado (1998), existe una notable ausencia de estudios rigurosos sobre la duración del fenómeno de desempleo para la economía canaria. El presente artículo se encargará de rellenar una parte de dicha laguna, mediante el estudio de la longitud del episodio del primer período de desempleo de los titulados de Formación Profesional Específica de cualquiera de los centros educativos de la isla de Gran Canaria, a través de la estimación de modelos de duración, con datos procedentes de una encuesta de elaboración propia.

En el siguiente apartado, describimos los datos que utilizamos en el presente estudio. A continuación, en el tercer apartado, realizamos estimaciones no paramétricas de la duración del primer período de desempleo, realizando previamente análisis de homogeneidad de estratos para su correcta interpretación. En ese mismo apartado especificamos diferentes modelos para la estimación paramétrica y seleccionamos el que presenta un mejor ajuste a nuestros datos. El cuarto apartado lo dedicamos a la interpretación de resultados de la estimación paramétrica. Finalmente, el quinto y último apartado recoge las principales conclusiones de nuestro artículo.

\section{Los datos}

Los datos usados en este estudio provienen de una encuesta telefónica propia, realizada a los alumnos que terminaron sus estudios de Formación Profesional Específica entre los cursos académicos 1997/98 a 1999/2000, en la isla de Gran Canaria (España). Realizamos la encuesta entre los meses de diciembre de 2001 y enero de 2002. Ésta contiene información referente a formación académica, características laborales y 
características socioculturales de cada uno de estos egresados.

El total de alumnos que constituyen la población objetivo ascendía a 4266 titulados distribuidos entre 21 familias profesionales. La encuesta se dirigió a toda la población para que la muestra definitiva fuese representativa de cada una de las familias profesionales, dado que, si optábamos por realizar un muestreo estratificado, debido a la enorme diferencia entre los tamaños de las familias profesionales, el tamaño muestral habría coincidido prácticamente con el tamaño poblacional. La única excepción la constituyó el caso de los titulados de la familia de Administración, quienes representaban casi un cuarto de la población total, que fueron seleccionados tras un muestreo aleatorio simple 4 . Finalmente, tras la finalización del trabajo de campo, la base de datos obtenida ascendió a 2776 titulados, habiéndose conseguido el objetivo inicial de buena representación de cada una de las familias, ya que para cada una de ellas se consiguió encuestar entre el 58\% y el $89 \%$ del total de egresados de la misma.

De estos 2776 titulados, hemos dirigido nuestro análisis, exclusivamente, al colectivo formado por los titulados que comenzaron su búsqueda de empleo una vez finalizado el Ciclo Formativo (CF), hayan o no tenido éxito en la misma, puesto que son los únicos para los que podemos hablar de un verdadero período de búsqueda de empleo tras la finalización del Ciclo Formativo ${ }^{5}$.

El período medio de búsqueda de empleo de aquellos que, en el momento de responder a la encuesta, habían conseguido su primer empleo, resulta ser de alrededor de dos meses. Dicha duración es superior para las mujeres -quienes tardan cerca de tres meses- que para los hombres, quienes tardan en torno al mes y medio en conseguir empleo. De la misma manera, la duración del primer período de desempleo de los técnicos es dos semanas mayor a la de los técnicos superiores. Igualmente, detectamos grandes diferencias en la duración del período de desempleo en función de la Familia Profesional a la que pertenezca el Ciclo Formativo cursado, siendo los titulados en 'Textil, Confección y Piel', junto con los de 'Química', quienes presentan una mayor duración (en torno a 4 meses), encontrándonos, por el lado contrario, con los titulados de 'Mantenimiento y Servicios a la Producción', que no tardan dos semanas en conseguir su primer empleo. Las diferencias en la duración de dicho periodo debidas a la titularidad del centro de estudios, en cambio, resultaron ser prácticamente inexistentes.

Entre los que aún no habían logrado su primer empleo en el

4 Este diseño muestral nos obliga a utilizar un factor de ponderación, que elimine el efecto de la infrarrepresentación de los titulados en 'Administración' en la muestra.

5 Esta muestra está compuesta por un total de 2054 titulados. 
El primer periodo desempleo de técnicos y técnicos superiores

momento de responder a la encuesta (78 titulados), el 75\% presentaba un período de búsqueda inferior al año y, tan sólo el $5 \%$ presentaba duraciones de desempleo superiores al año y medio, por lo que prácticamente no nos encontramos ante ningún caso de paro de larga duración ${ }^{6}$.

Como se puede apreciar, la duración del desempleo de nuestra base de datos es generalmente breve. De hecho, la tasa de salida del desempleo al día siguiente de comenzar a buscar trabajo es del $42.6 \%$ para los hombres y del $37 \%$ para las mujeres. Esta tasa, sigue siendo alta aún durante la primera semana, en donde los hombres presentan una tasa de salida del 19\% y las mujeres del $9.7 \%$. Las diferencias en cuanto a tasas de salidas del desempleo, se acentúan aún más si realizamos el análisis por Familias Profesionales, pues nos podemos encontrar con el caso de los titulados en 'Actividades Físicas y Deportivas', 'Edificación y Obra Civil', 'Imagen Personal' o 'Mantenimiento y Servicios a la Producción', quienes presentan una tasa de salida superior al $60 \%$ en el primer día de búsqueda, frente a los titulados en 'Química' o 'Sanidad', quienes no llegan a una tasa de salida del $30 \%$.

\section{El modelo}

El análisis de la duración del primer período de desempleo lo realizaremos en dos etapas: 1. mediante una estimación no paramétrica, en la que analizamos exclusivamente el período de duración, sin tomar en consideración ninguna otra variable que pueda influir sobre el mismo; 2 . mediante una estimación paramétrica, en donde realizamos supuestos acerca de la posible distribución de las duraciones de salida de la situación de desempleo, a la vez que analizamos el efecto de diferentes variables sobre dicha duración.

\subsection{Estimación no paramétrica}

Comenzamos el análisis mediante la estimación de las funciones empíricas de densidad, distribución y riesgo, a través de la metodología propuesta por Kaplan y Meier (1958). Dichos autores sugieren que el cálculo de las funciones se realice de forma tal que, al agrupar la información por intervalos, estos recojan la información de un único individuo, sea esta finalización real o censura. Por tanto, hemos delimitado los extremos de los intervalos en las duraciones de desempleo,

6 Todo el análisis realizado en el presente artículo se mantiene sin variación incluyendo o eliminando a este 5\%-. Por ello hemos decidido trabajar con el total de los datos, siendo así fieles a la información obtenida en la encuesta. 
medidas en días, manifestadas por los titulados de nuestra muestra.

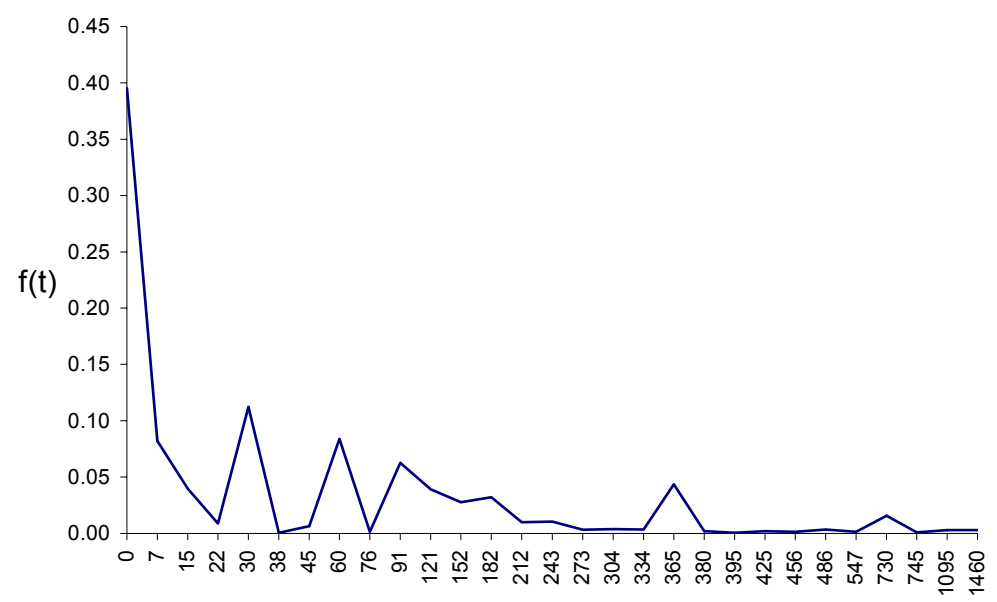

\section{Gráfico 1: Función empírica de densidad de la duración del desempleo previo al primer empleo (Kaplan-Meier)}

Analizando la función de densidad empírica recogida en el Gráfico 1 -que refleja la distribución porcentual de la duración del primer período de desempleo de la muestra de técnicos y técnicos superiores- vemos que cerca del $40 \%$ de los titulados dijeron haber encontrado empleo nada más comenzar a buscarlo, por lo que presentan una duración de desempleo de 0 días. Igualmente se observa una cierta concentración en las duraciones de desempleo equivalentes a 1 semana (8\%), 1 mes (11\%), 2 meses $(8 \%)$ y 3 meses $(6 \%)$, distribuyéndose el resto de las duraciones, fundamentalmente entre los períodos de 4 y 6 meses (4\% y $3 \%$ respectivamente) y de 1 año (4\%). De esta distribución se puede deducir que los titulados presentan una cierta tendencia a redondear, a la hora de responder a la pregunta referida a la duración de su período de búsqueda de empleo. Así, aquellos que tardaron menos de un mes, probablemente optaron por redondear en semanas, mientras que los que tardaron más de un mes, optaron por redondear, fundamentalmente, en meses. Este patrón de comportamiento, por otra parte típico cuando se utiliza el método retrospectivo a la hora de recopilar la información (ver D’Agostino y Mealli, 2000, GutiérrezDomenech, 2002 o Bover y Gómez, 2004, entre otros), nos facilitará la agrupación de los datos en intervalos, con la finalidad de realizar la estimación a través del cálculo actuarial ${ }^{7}$.

7 Dado que no nos encontramos prácticamente ante ningún caso de paro de larga duración, los posibles problemas de redondeo no resultan significativos como para tener que tomar ninguna medida en nuestras estimaciones. 
La estimación de la función de distribución empírica, es decir, de la proporción acumulada de los distintos períodos de duración, nos muestra cómo cerca del $52 \%$ de los titulados presenta una duración del primer período de desempleo inferior a las dos semanas; en torno al 64\% de los titulados, presenta una duración inferior al mes; el 73\% permanece menos de 2 meses desempleados antes de lograr su primer trabajo; cerca del 90\% ha conseguido su primer empleo transcurridos 6 meses de búsqueda; y, finalmente, el $96.6 \%$ lo ha conseguido una vez transcurrido el primer año de búsqueda.

Cuadro 1: Tabla de vida de la duración del desempleo previo al primer empleo

\begin{tabular}{rrrrrrccccc}
\hline & & Total & $\begin{array}{c}\text { Fina- } \\
\text { lizan }\end{array}$ & $\begin{array}{r}\text { Cen- } \\
\text { sura }\end{array}$ & $q$ & $p$ & $\begin{array}{c}\text { Func. de } \\
\text { Superv. }\end{array}$ & $f$ & $\begin{array}{c}\text { Func. de } \\
\text { Distrib. }\end{array}$ & $\begin{array}{c}\text { Func. } \\
\text { de Riesgo }\end{array}$ \\
\hline 0 & 7 & 2054 & 811 & 4 & 0,395 & 0,605 & 0,605 & 0,056 & 0,395 & 0,070 \\
7 & 15 & 1239 & 168 & 2 & 0,136 & 0,864 & 0,523 & 0,010 & 0,477 & 0,018 \\
15 & 30 & 1069 & 99 & 3 & 0,093 & 0,907 & 0,474 & 0,003 & 0,526 & 0,007 \\
30 & 60 & 967 & 242 & 5 & 0,251 & 0,749 & 0,355 & 0,004 & 0,645 & 0,010 \\
60 & 90 & 720 & 172 & 10 & 0,241 & 0,759 & 0,270 & 0,003 & 0,730 & 0,009 \\
90 & 120 & 538 & 124 & 9 & 0,232 & 0,768 & 0,207 & 0,002 & 0,793 & 0,009 \\
120 & 150 & 405 & 76 & 4 & 0,189 & 0,811 & 0,168 & 0,001 & 0,832 & 0,007 \\
150 & 180 & 325 & 53 & 4 & 0,164 & 0,836 & 0,141 & 0,001 & 0,860 & 0,006 \\
180 & 210 & 268 & 60 & 13 & 0,229 & 0,771 & 0,108 & 0,001 & 0,892 & 0,009 \\
210 & 240 & 195 & 18 & 0 & 0,092 & 0,908 & 0,098 & 0,000 & 0,902 & 0,003 \\
240 & 270 & 177 & 19 & 1 & 0,108 & 0,892 & 0,088 & 0,000 & 0,912 & 0,004 \\
270 & 300 & 157 & 6 & 0 & 0,038 & 0,962 & 0,084 & 0,000 & 0,916 & 0,001 \\
300 & 330 & 151 & 7 & 2 & 0,047 & 0,953 & 0,080 & 0,000 & 0,920 & 0,002 \\
330 & 360 & 142 & 6 & 1 & 0,042 & 0,958 & 0,077 & 0,000 & 0,923 & 0,001 \\
360 & 540 & 135 & 86 & 16 & 0,677 & 0,323 & 0,025 & 0,000 & 0,975 & 0,006 \\
540 & 720 & 33 & 2 & 1 & 0,062 & 0,938 & 0,023 & 0,000 & 0,977 & 0,000 \\
720 & 900 & 30 & 21 & 3 & 0,737 & 0,263 & 0,006 & 0,000 & 0,994 & 0,007 \\
\hline 1080 &. & 6 & 6 & 0 & 1,000 & 0,000 & 0,000 &. & 1,000 &. \\
\hline
\end{tabular}

Por último, la estimación de la función de riesgo empírica, es decir, de la probabilidad condicional de que el individuo que ha estado parado hasta el instante $t$ deje de estarlo en el período inmediatamente posterior, nos muestra cómo los períodos que presentan una mayor probabilidad condicional de abandono de la situación de desempleo son, precisamente, el instante cero (39.5\%), el año (53.3\%), los dos años (63.3\%) y los 4 años $(100 \%)^{8}$. Aunque la probabilidad condicional de abandono también es

8 Ésta es la máxima duración muestral, por lo que es de esperar que su riesgo de salida 
relativamente alta para los que han llegado a una duración de desempleo de 1, 2, 3 y 6 meses (en torno al 23\%).

En la mayoría de los casos es preferible realizar la estimación de la función de riesgo una vez agrupados los datos en intervalos, puesto que de esta manera se puede detectar con mayor claridad qué tipo de relación de dependencia mantiene dicha función con el tiempo. Es por ello, por lo que optamos por la realización de las estimaciones nuevamente, pero esta vez, a través del cálculo actuarial, obteniendo de esta manera la tabla de vida que recogemos en el Cuadro 1.

En él mostramos, en primer lugar, los extremos superior e inferior del intervalo (Intervalo); el número de supervivientes al inicio de cada intervalo (Tota); el número de titulados que consiguen empleo durante él (Finalizan) y el número de observaciones censuradas en el mismo (Censura). A continuación estimamos la proporción de sucesos terminales $(q)$, es decir, la probabilidad de que una observación que entra en el intervalo i-ésimo encuentre empleo dentro de él ${ }^{9} \mathrm{y}$, seguidamente, recogemos su complementario $(p)$, es decir, la probabilidad de supervivencia en el intervalo i-ésimo. La siguiente columna recoge la estimación de la función de supervivencia empírica al final del intervalo, obtenida como $p_{i} S_{i-1}$ (función de supervivencia); mientras que la siguiente, que recoge la densidad de probabilidad ( $)$, es una estimación de la probabilidad de finalización del evento por unidad de tiempo. Mediante esta última medida se intenta expresar una probabilidad instantánea, propia de la función de densidad probabilística, a través de una distribución discreta, obtenida como la fracción entre la disminución de probabilidad acumulada de supervivientes del intervalo y la amplitud del mismo: $\left(S_{i-1}-S_{i}\right) /$ amplitud . Por último, recogemos la estimación de la función complementaria a la de supervivencia (función de distribución) y la estimación de la probabilidad de conseguir empleo por unidad de tiempo suponiendo que el titulado ha permanecido desempleado hasta el inicio del intervalo (función de riesgo) ${ }^{10}$.

del desempleo sea el máximo.

9 Esta estimación se realiza corrigiendo el efecto de las observaciones censuradas. Dado que las observaciones censuradas no están expuestas al riesgo de conseguir empleo durante todo el intervalo, sino tan sólo durante el tiempo en que son observables, este método asume tan sólo la mitad de su posible contribución, por lo que el cálculo de la proporción de sucesos terminales se realiza según la siguiente expresión:

$$
q_{i}=\frac{\text { finalizan }_{i}}{\text { total }_{i}-1 / 2 \text { censura }_{i}}
$$

${ }^{10}$ Este último valor se obtiene mediante la siguiente expresión:

$$
h_{i}=\frac{f_{i}}{1 / 2\left(S_{i-1}+S_{i}\right)}
$$


La estimación de la función de distribución a partir del cálculo actuarial nos proporciona prácticamente los mismos valores que la estimación a través de la metodología de Kaplan y Meier, aunque con ligeras diferencias debidas a la corrección que se realiza en el cálculo actuarial ante la presencia de censura en los datos. Por tanto, los valores recogidos en la penúltima columna del Cuadro 1 coinciden prácticamente con los resultados obtenidos en el cálculo de la función de distribución empírica ya comentada.

Sin embargo, a la hora de estimar la función de riesgo mediante el cálculo actuarial, los valores obtenidos son muy diferentes a los que proporciona la estimación de Kaplan-Meier, debido al hecho de que la información, en esta ocasión, aparece agrupada en intervalos, con la consiguiente distribución del riesgo a lo largo del mismo. Es por ello, por lo que el riesgo estimado de esta manera, toma valores mucho menores. No obstante, esta metodología nos permite descubrir de forma más nítida la relación de dependencia existente entre la función de riesgo y el tiempo. En este caso, dicha relación es negativa, puesto que la probabilidad condicionada de que un episodio de desempleo finalice resulta ser menor cuanto mayor ha sido la longitud de dicho episodio. Según comentan Eckstein y Van Den Berg (2002), éste es el comportamiento habitual de la función de salida del desempleo, cuando se realiza la estimación paramétrica de máxima verosimilitud propuesta por Kaplan y Meier.

La representación gráfica de la función de supervivencia obtenida mediante el cálculo actuarial la recogemos mediante el Gráfico $2^{11}$. En lugar de realizar una representación conjunta para toda la muestra, hemos optado por graficar dichas funciones segregando la muestra en función del género, del nivel del Ciclo Formativo y de la titularidad del centro de estudios, con la finalidad de detectar si existen diferencias entre estos colectivos en lo que respecta a la duración de ese primer período de desempleo ${ }^{12}$.

De la mera observación de dichas ilustraciones, se desprenden las diferencias en cada una de ellas, puesto que las curvas graficadas no se superponen unas a otras. Sin embargo, resulta conveniente realizar previamente un análisis de homogeneidad de los estratos que nos confirme la existencia de diferencias significativas entre cada uno de los diferentes

11 Al tratarse de la representación de una tabla de vida en la cual las duraciones han sido agrupadas en intervalos, el valor que aparece representado al comienzo de cada intervalo, debe considerarse como un valor estable a lo largo del mismo, hasta el comienzo del siguiente. La representación gráfica exacta de dicha tabla debería mostrar gráficas escalonadas, en lugar de continuas.

12 No incluimos la gráfica que diferencia por Familias Profesionales puesto que, al tratarse de 21 Familias Profesionales diferentes, resulta difícil distinguir su contenido. 
colectivos. No obstante, las posibilidades de realización de contrastes de homogeneidad se ven reducidas por el hecho de trabajar con una muestra ponderada.
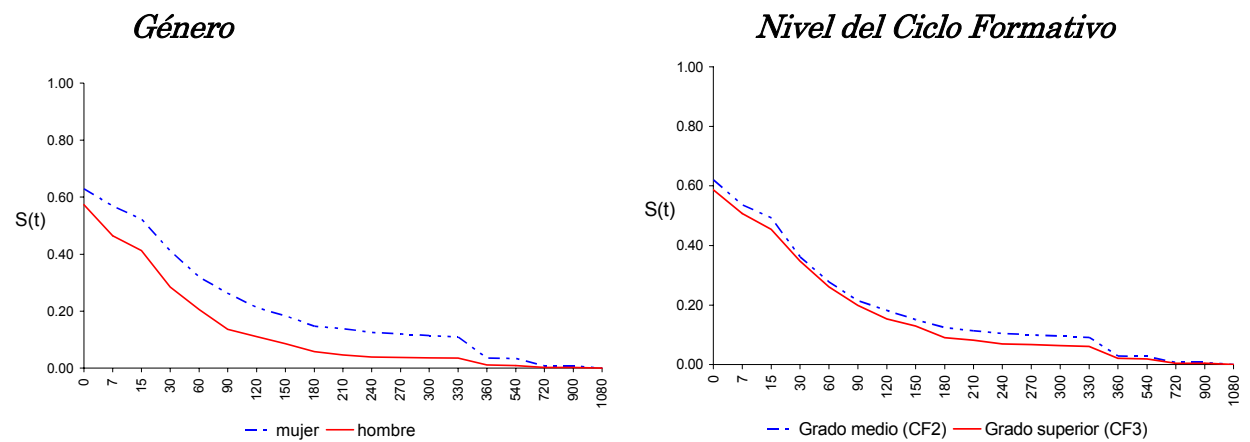

Titularidad del centro de estudios

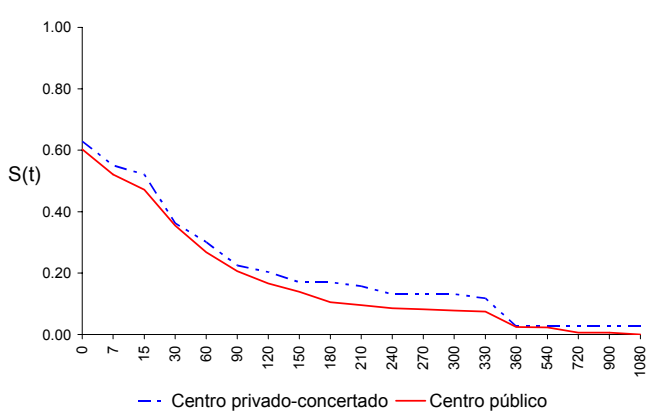

\section{Gráfico 2: Función de supervivencia de la duración del desempleo previo al primer empleo}

Dada la existencia de censura en los datos, los contrastes de igualdad de poblaciones independientes de Wilcoxon y Mann-Whitney no son aplicables, pero, si a esto añadimos que la muestra está ponderada, el único contraste de homogeneidad aplicable es el contraste de 'Cox' (StataCorp., 2001)13, el cual, a su vez, está basado en el log-rank test propuesto por Mantel y Haenszel (1959).

Tras la realización del contraste de homogeneidad de 'Cox' a las diferentes estratificaciones propuestas, obtenemos los siguientes resultados.

De los valores observados de los estadísticos de prueba podemos concluir que existe evidencia que permite rechazar la hipótesis nula de

${ }^{13}$ El término de contraste de 'Cox' ha sido acuñado en el manual de referencias del programa Stata, puesto que se trata de un contraste de log-rank que utiliza regresiones de Cox. Para una explicación más exhaustiva, consultar el Anexo A.1. 
igualdad de las funciones de riesgo (y, por tanto, de supervivencia y distribución), en el caso de la estratificación de la muestra por género, nivel del Ciclo Formativo y Familias Profesionales. En cambio, en lo que respecta a la diferenciación por titularidad del centro, el contraste de homogeneidad de 'Cox' no aporta evidencia que nos permita rechazar dicha hipótesis.

Cuadro 2: Contrastes de homogeneidad de estratos para el análisis de la duración del desempleo previo al primer empleo

\begin{tabular}{lrc}
\hline \multicolumn{1}{c}{ Estratos } & Estadístico & Probabilidad \\
\hline Género & 47,03 & 0,0000 \\
Nivel del Ciclo Formativo & 4,88 & 0,0271 \\
Titularidad del centro & 0,81 & 0,3685 \\
Familias Profesionales & 155,64 & 0,0000 \\
\hline
\end{tabular}

El análisis diferenciado por género nos muestra cómo, en todos los períodos de duración, la probabilidad condicionada de abandonar la situación de desempleo es superior para los hombres que para las mujeres, al igual que lo es la probabilidad no condicionada de salir de esa situación de desempleo. Se observa la misma relación de dependencia negativa entre la función de riesgo y el tiempo, tanto para el caso de los hombres, como para el de las mujeres, sufriendo esta función pequeños repuntes, siempre superiores entre los hombres, en los períodos de 1 mes, 3 meses y 6 meses de desempleo.

Tanto los hombres, como las mujeres, presentan una alta probabilidad de salida del desempleo en un período inferior a una semana, siendo ésta del $42.6 \%$ para los hombres y del $37 \%$ para las mujeres. A partir de esa duración, hasta llegar al año, las diferencias en la probabilidad no condicionada de conseguir un primer empleo, son acusadas entre hombres y mujeres, con una clara ventaja, de en torno al $10 \%$, para los primeros. Al cabo del año las diferencias se acortan, pasando a ser tan sólo del 2.3\%. Mientras que, al llegar a los 2 años de desempleo, prácticamente no existen diferencias por género.

Diferenciando la muestra entre técnicos y técnicos superiores se observa que las diferencias entre ambos colectivos -en la probabilidad de salida del desempleo- son bastante menos acusadas que las diferencias detectadas por género, aunque al analizar la distribución de la probabilidad no condicionada de salida $F(t)$ o de permanencia $S(t)$, comprobamos cómo los técnicos superiores presentan una cierta ventaja 
sobre los técnicos en períodos inferiores al año. Las mayores diferencias entre estos dos colectivos surgen tras los 4 y 6 meses de desempleo, momento en el cual los técnicos superiores experimentan mayores probabilidades de salida en su función de riesgo.

A partir de las funciones de distribución y de supervivencia, diferenciando a los egresados en función de la titularidad de su centro de estudios, podríamos suponer que los titulados de centros privados se enfrentan a peores oportunidades en el mercado de trabajo. No obstante, la función de riesgo nos muestra una pauta ambigua, puesto que ambas curvas aparecen entrelazadas a lo largo de todos los períodos de duración. En cualquier caso, la realización del contraste de homogeneidad de 'Cox' ya nos indicaba que no parecían existir diferencias estadísticamente significativas en función de la titularidad del centro de estudios.

Por último, dividiendo la muestra por Familias Profesionales se detectan diferencias bastante acusadas entre ellas. Ya de entrada, la función de riesgo durante la primera semana de desempleo toma valores tan dispares como el 2.5\% para 'Actividades Agrarias' o el 13.6\% de 'Mantenimiento y Servicios a la Producción', cuando el valor medio de la muestra para esa duración es del 7\%. La probabilidad condicionada de abandono del desempleo durante la segunda semana es, con diferencia, para los titulados de 'Mantenimiento de Vehículos Autopropulsados', la mayor de todas $(6.4 \%$ frente a probabilidades inferiores al $3 \%$ para el resto). Esta situación se repite, para la probabilidad condicionada de salida durante el segundo mes de desempleo, en el caso de los titulados en 'Industrias Alimentarias' (6.6\%) y 'Mantenimiento y Servicios a la Producción' (4.8\%). En el cuarto mes, la ventaja es para los titulados en 'Madera y Mueble' (6.6\%). Mientras que, en el quinto mes, la ventaja es para los de 'Fabricación Mecánica' (6.5\%) y 'Actividades Marítimo Pesqueras' (6.6\%).

Las funciones de distribución y supervivencia nos muestran cómo la Familia Profesional que se enfrenta a peores oportunidades laborales en el mercado de trabajo, parece ser la de 'Textil, Confección y Piel', puesto que, al cabo de tres años, aún mantiene una proporción de desempleo del $13.3 \%$, cuando en el resto de las familias, este porcentaje no llega al $3 \%$. Por el lado contrario, la Familia Profesional que se enfrenta a las mejores oportunidades laborales es la de 'Mantenimiento y Servicios a la Producción', puesto que, al cabo de los dos meses, presenta una proporción de desempleados de tan sólo el $2 \%$.

En líneas generales se puede observar que, transcurridos tres meses desde el comienzo de la búsqueda de empleo, la probabilidad de mantenerse en situación de desempleo es inferior al 50\% para todas las Familias Profesionales (desde el 40\% para 'Textil, Confección y Piel' hasta 
el $0 \%$ para 'Madera y Mueble'). Transcurridos seis meses, esta probabilidad es inferior al 20\% para todas las familias, con la excepción de 'Textil, Confección y Piel' (40\%) y 'Química' (32.7\%), Y, finalmente, transcurrido un año, la probabilidad de continuar desempleado es inferior al 5\% en todos los casos, con la excepción de los titulados en 'Textil, confección y Piel' (13\%).

\subsection{Estimación paramétrica}

Una vez finalizado el análisis no paramétrico, pasamos a analizar cuáles son los rasgos más significativos que rigen el período de transición entre la finalización de los estudios y el acceso al mercado de trabajo. De esta manera trataremos de comprobar qué características individuales, así como qué factores del entorno económico, inciden sobre la probabilidad de encontrar el primer empleo tras la finalización de los estudios.

El marco teórico del análisis se encuadra en el modelo de búsqueda de empleo de Holzer (1988), según el cual los individuos desempleados actuarán conforme a un proceso de búsqueda de empleo que trate de maximizar la suma de sus utilidades actuales y esperadas.

La utilidad actual dependerá de los ingresos menos el coste monetario de la búsqueda de empleo y de la diferencia entre el valor del tiempo de ocio y el coste del tiempo dedicado a la búsqueda. A su vez, la utilidad esperada dependerá de la probabilidad de estar empleado o desempleado en el futuro, que es función de la distribución probabilística de la oferta de empleos y de la oferta salarial.

Bajo la especificación de Holzer hay que tener en cuenta que la productividad de cada método de búsqueda de empleo disminuye cuando su coste aumenta, siendo diferentes entre individuos tanto el coste como la productividad en función de sus características socioeconómicas.

Este modelo, por tanto, concuerda con la aportación de Nickell (1979), quien desarrolló un sencillo modelo de búsqueda de empleo a través del cual concluyó que la probabilidad de abandonar el desempleo era una constante que dependía de un vector de características individuales $x$ y de otras variables que afectaban al salario de reserva.

Por otro lado, el análisis de los determinantes de la duración del desempleo no se puede llevar a cabo sin contemplar las aportaciones a los modelos de búsqueda de empleo de Mortensen (1986) y Devine y Kiefer (1991), quienes comentan que, la tasa de salida del desempleo se puede obtener, mediante la multiplicación de la probabilidad de obtener una oferta de empleo por la probabilidad de que dicha oferta sea aceptable. La tasa de llegada de ofertas, según estos autores, será función de la demanda de trabajo para las características del individuo considerado y para su esfuerzo de búsqueda. 
Por tanto, la especificación del modelo causal paramétrico, que explica la duración del primer período de desempleo, se realizará, incorporando como covariables, aquellas que emanen de las aportaciones teóricas de los autores mencionados previamente.

En la línea argumental de Mortensen (1986) y Devine y Kiefer (1991), Congregado-Ramírez y García-Pérez (2002) consideran que, el componente de demanda de trabajo, que afecta a la tasa de llegada de ofertas, puede ser captado mediante la utilización de variables agregadas, como pueden ser la tasa de crecimiento del PIB o la tasa de desempleo de la zona de residencia del individuo. Igualmente consideran que, la tasa de llegada de ofertas, depende también de la red de contactos del individuo, optando por introducir como indicador de dicha red, el número de contactos que puedan ofrecerles sus progenitores, a través de la introducción del nivel de formación y la situación profesional de los mismos, como proxy para dicha red. Por último, como factor del lado de la demanda de trabajo que puede tener un efecto significativo sobre la probabilidad de recibir una oferta de empleo, consideran la utilidad de introducir variables de localización como indicadores de la tasa de desempleo regional.

En lo que respecta a la disposición de los individuos a aceptar una oferta laboral, ésta puede venir determinada por las expectativas que tenga el trabajador sobre las posibles ofertas futuras, así como por sus preferencias por el trabajo, en la medida en que estos factores influyen en la determinación de su salario de reserva. No obstante, dado que estas variables no son directamente observables, se puede utilizar como aproximación a las mismas la edad, el nivel educativo o el lugar de residencia (Congregado-Ramírez y García-Pérez, 2002).

Sin embargo, estas características personales de edad y nivel educativo, como componentes del lado de la oferta de trabajo, no presentan de antemano un efecto claro sobre la probabilidad de la duración del desempleo (Lázaro-Pardo et al., 2000). De hecho, la educación aumenta, cæteris paribus, la probabilidad de recibir una oferta de empleo, pero también disminuye la probabilidad de aceptar una determinada oferta salarial, puesto que el salario de reserva aumenta con el nivel educativo. Igualmente, la edad disminuirá la probabilidad de recibir ofertas de empleo, a la vez que disminuirá el salario de reserva y, por tanto, aumentará la probabilidad de aceptar la oferta salarial. Por lo que, introducir dichas covariables en el modelo de duración, no conlleva unas expectativas previas claras en cuanto a su influencia sobre la duración del primer período de desempleo.

En lo que respecta al salario de reserva, que, como hemos comentado, influye directamente en la duración del período de desempleo, 
éste también se ve afectado por la percepción o no de una prestación por desempleo (Lázaro-Pardo et al., 2000 y Bover et al., 2002), en el sentido de que si se está cobrando dicha prestación, el salario de reserva aumenta, reduciendo, por tanto, la probabilidad de aceptar un empleo y aumentando así la duración del desempleo. No obstante, dado que nuestro modelo se centra en el período de desempleo previo al primer trabajo de los técnicos y técnicos superiores, no cabe la posibilidad de que éstos estén cobrando prestación por desempleo, puesto que aún no han conseguido su primer trabajo. De todas formas, Han y Hausman (1990) comprobaron que, a pesar de que dicha prestación tenía un efecto importante en la determinación de la duración del período de desempleo, el efecto de las variables sociodemográficas sobre dicha duración era considerablemente superior.

Otro factor que influye sobre el salario de reserva es la situación económica en el momento de la búsqueda de empleo, así como las expectativas sobre el futuro. Concretamente, cabría esperar que el salario de reserva fuera menor en períodos de recesión o en zonas con peor situación económica. No obstante, a la hora de estimar nuestro modelo, no podremos hacer uso de la variable 'salario de reserva' puesto que solamente disponemos de dicha información para el caso de los titulados que aún no habían conseguido su primer empleo, pero no en los que sí lo habían logrado.

La aceptación o no de una oferta laboral vendrá también determinada por la situación familiar del individuo (Bratberg y Nilsen, 2000), por lo que también tendremos que incluir variables que hagan referencia a dicha situación en el modelo de duración. Es más, Ahn y Ugidos-Olazábal (1995) comentaron, en su estudio sobre el efecto del subsidio por desempleo y de las características familiares sobre la duración del desempleo en España, que, dado que dicho subsidio tenía una duración limitada, un factor que revelaba tener una gran importancia a la hora de explicar la alta tasa de desempleo española eran, precisamente, las características familiares, y más concretamente, el apoyo económico familiar.

\subsubsection{Elección del mejor modelo}

La variable endógena del modelo es el tiempo transcurrido entre el comienzo de búsqueda del primer empleo y la consecución del mismo, para los titulados que buscaron su primer empleo tras la finalización del Ciclo Formativo. Ésta es una variable aleatoria continua $\mathrm{T}$ que presenta censura por la derecha en el 3.8\% de los casos.

Para la estimación de un modelo, que explique la variabilidad de dicha duración en función de un conjunto de covariables, disponemos de 
un amplio abanico de distribuciones de probabilidad. El problema radica en la elección de la distribución más apropiada a los datos.

Kiefer (1988) comenta al respecto que, para la elección del modelo paramétrico más adecuado a los datos, resulta útil recurrir a la información aportada por las estimaciones no paramétricas de las funciones de riesgo. En nuestro caso, la estimación no paramétrica de la duración del período de desempleo previo al primer empleo, parecía reflejar, en líneas generales, un decrecimiento monótono (Gráfico 1), por lo que los modelos más adecuados resultan ser el modelo paramétrico de Weibull y el de Gompertz. De hecho, estos dos modelos se suelen implementar en la modelización de datos que presentan tasas de riesgo monótonas, tanto crecientes como decrecientes (StataCorp., 2001).

Tras las consideraciones teóricas realizadas hasta el momento, observamos que, el efecto esperado de algunas de las posibles variables explicativas a incorporar en el modelo puede resultar ambiguo, debido a que las mismas pueden afectar tanto a la probabilidad de recibir una oferta laboral, como a la probabilidad de aceptar la misma. Por tanto, será el análisis empírico, el que resuelva dicha ambigüedad, proporcionándonos un resultado en función del efecto que prevalezca.

Las variables independientes que hemos seleccionado para explicar la duración del desempleo, las podemos agrupar en cuatro bloques ${ }^{14:}$

1. Características personales y familiares:

En este bloque recogemos aquellos factores propios del individuo que, al poder influir en la probabilidad de recibir ofertas laborales, o en la probabilidad de aceptar las mismas, pueden afectar a la duración de su período de desempleo, como es el caso de las variables SEXO, EDAD1 y EXPPREV.

Igualmente introducimos características de su entorno familiar, como medida de aproximación a las obligaciones o cargas familiares que tenía el titulado al finalizar el CF, y que, por tanto, pueden afectar a la determinación del salario de reserva y, en consecuencia, a la mayor o menor duración del primer período de desempleo (HIJOS1, NTRABAJ1, INGRHOG1).

Y, por último, al igual que hicieron Theeuwes (1989), Biggeri et al. (2001) y Congregado-Ramírez y García-Pérez (2002), incorporamos, como explicativas de la duración del desempleo del titulado, el nivel formativo del cabeza de familia (ESTCABFS), así como su situación laboral (CABFAOCUPA1), pues consideramos que estos factores influyen en la probabilidad de recepción de ofertas laborales del titulado. Estos dos factores vienen recogidos mediante las variables siguientes:

\section{Características educativas:}

\footnotetext{
${ }^{14}$ Para una definición exacta de cada una de las variables consultar el Anexo A.2.
} 
En este bloque recogemos aquellas características que se refieren a la formación académica del titulado y que, en consecuencia, esperamos que influyan sobre la probabilidad de recibir ofertas laborales, afectando así a la duración del período de desempleo, como son las variables NIVELCF, FAMILIAP, ACCDIREC, PUB_PRI, MALESTUD, FIN, TARDAPREV y NOTASUP.

3. Variables de entorno:

Con el fin de captar la influencia de las condiciones del mercado de trabajo sobre la duración del período de búsqueda del primer empleo, hemos optado por introducir variables que hagan referencia a la zona geográfica en la que el titulado estudió (RUR_URB) ${ }^{15}$, así como variables que recojan el efecto del ciclo económico. Estas últimas las recogemos a través de la introducción de la tasa de desempleo juvenil (TASADESJ), en la fecha en la que el titulado consigue el empleo ${ }^{16}$, así como mediante la introducción de dicotómicas que recojan el año en el que los titulados consiguen su primer empleo (AÑOCM_). Las variables que introducimos en este bloque son:

4. Características del proceso de búsqueda:

Finalmente, el cuarto bloque de variables explicativas hace referencia al proceso de búsqueda de empleo, puesto que este proceso estará directamente relacionado con la probabilidad de obtener ofertas de trabajo por parte de los titulados. Dentro de este bloque se encuentran las variables NMEDBUS1, CURRIC1, INEM1, ETT1, PRENSA1, CONTACT1, FCT1, BOLSAST1 y OPOSIC1.

Aún introduciendo estos cuatro bloques de variables explicativas en nuestro modelo, siempre podrán existir otras variables que no hayamos observado y que influyan en la función de riesgo, pudiendo causar, de esta manera, un problema de heterogeneidad inobservable en los modelos estimados.

El hecho de no controlar por la posible heterogeneidad durante el proceso de estimación, nos llevaría a un sesgo en las inferencias acerca de las relaciones de dependencia (Lancaster, 1992), por lo que deberíamos estudiar la posible existencia de heterogeneidad en nuestros datos.

Según Lancaster (1992), la existencia de heterogeneidad inobservable entre individuos es un problema habitual que puede venir motivado por tres factores: a) error en la medición de las duraciones, b) error en la medición de las covariables y c) omisión de variables

15 Suponemos que si el titulado estudió en un centro educativo de la ciudad de Las Palmas de Gran Canaria, buscará su primer empleo en esa misma ciudad; mientras que si estudió fuera de la ciudad, buscará su primer empleo fuera de ella.

${ }^{16}$ En el caso de los titulados que aún no habían conseguido su primer empleo, tomamos la tasa de desempleo existente en el mercado al responder la encuesta. 
relevantes.

En la estimación de nuestro modelo, aunque quepa la posibilidad de tener errores de medición de la duración, puesto que ésta se basa en el tiempo que los encuestados 'recuerdan' haber dedicado a la búsqueda, es más probable que, en caso de tener heterogeneidad inobservable, ésta sea debida a la existencia de regresores no observables y, en consecuencia, omitidos. Éste puede ser el caso del propio salario de reserva de los titulados, o de la posible percepción de subsidio de desempleo, por parte de los titulados que han reconocido haber disfrutado de un empleo previo a la finalización de sus estudios.

Lancaster (1992) señala también que la heterogeneidad puede derivarse igualmente de las condiciones de incertidumbre en las que se realiza el proceso de búsqueda por parte de los desempleados, $\mathrm{y}$, por tanto, de las diferencias en el éxito de dichos procesos de búsqueda. No obstante, al introducir las variables enumeradas previamente en el cuarto bloque, recogemos, de alguna manera, el esfuerzo de búsqueda realizado por los egresados de nuestra muestra, con lo que deberíamos reducir la heterogeneidad causada por este motivo.

La forma típica de controlar el fenómeno de la heterogeneidad inobservable, consiste en asumir que el término de perturbación aleatoria del modelo proviene de una función de distribución paramétrica determinada, teniendo que estimar así los parámetros de la función de distribución que genera estos errores.

La teoría no proporciona una pauta clara que nos permita decidir qué función de distribución debe utilizarse para el término de heterogeneidad, aunque son muchos los estudios empíricos que se decantan por la heterogeneidad gamma (Lancaster, 1979; Theeuwes, 1989; Han y Hausman, 1990; Melkersson, 1999; Petrongolo, 2001; GámezAmián y García-Pérez, 2002; Kettunen, 2002).

Nosotros optamos por estimar modelos de duración Weibull y Gompertz introduciendo, como posible heterogeneidad inobservada, la derivada de una variable Gamma de media 1 y varianza $\theta$ (ver Lancaster, 1992 o Klein y Moeschberger, 1997), así como la derivada de una variable Gaussiana Inversa de media 1 y varianza 1/O (ver StataCorp., 2001). Las medidas de bondad del ajuste de estas cuatro especificaciones son las que vienen recogidas en el Cuadro 3.

El resultado del contraste de hipótesis de heterogeneidad inobservable, cuya hipótesis nula plantea la ausencia de dicho problema, nos permite concluir en los cuatro casos estimados, que el término estimado de $\sigma^{2}$ es estadísticamente significativo y que, en consecuencia, la heterogeneidad inobservable resulta relevante.

Resulta razonable plantearse cómo seleccionar el modelo 
paramétrico más adecuado, dado que tenemos varias alternativas a elegir. Si los modelos hubiesen estado anidados, podríamos utilizar un contraste de ratio de verosimilitudes o un contraste de Wald para discriminar entre ellos. Éste tipo de contrastes sería válido en caso de tener que optar entre una distribución Weibull y una Exponencial, o entre una distribución Gamma, una Weibull o una Log-normal ${ }^{17}$. Sin embargo, cuando los modelos no están anidados, como es nuestro caso, la discriminación entre ellos no se puede realizar de esta manera.

\section{Cuadro 3: Medidas de bondad del ajuste de la estimación paramétrica y contraste de existencia de heterogeneidad inobservable}

\begin{tabular}{lcccc}
\hline & $\begin{array}{c}\text { Weibull con } \\
\text { heterogeneidad } \\
\text { gamma }\end{array}$ & $\begin{array}{c}\text { Weibull con } \\
\text { heterogeneidad } \\
\text { gaussiana inversa }\end{array}$ & $\begin{array}{c}\text { Gompertz con } \\
\text { heterogeneidad } \\
\text { gamma }\end{array}$ & $\begin{array}{c}\text { Gompertz con } \\
\text { heterogeneidad } \\
\text { gaussiana inversa }\end{array}$ \\
\hline $\begin{array}{l}\mathrm{Chi}^{2}{ }_{51} \\
\text { Log. Vero- } \\
\text { similitud }\end{array}$ & $-499,880 \mathrm{p}=0,000$ & $1060,070 \mathrm{p}=0,000$ & $2040,640 \mathrm{p}=0,000$ & $1275,370 \mathrm{p}=0,000$ \\
$\mathrm{AIC}$ & 10085,279 & $-5038,526$ & $-4873,841$ & $-5019,127$ \\
$H_{0}: \sigma^{2}=0$ & 10181,051 & 9851,681 & 10142,253 \\
$\mathrm{~N}^{\mathrm{o}}$ observ. & $\bar{\chi}_{1}^{2}=227,98$ & $\bar{\chi}_{1}^{2}=155,63$ & $\bar{\chi}_{1}^{2}=1004,36$ & $\bar{\chi}_{1}^{2}=811,60$ \\
& $\mathrm{p}=0,000$ & $\mathrm{p}=0,000$ & $\mathrm{p}=0,000$ & $\mathrm{p}=0,000$ \\
& 1691 & 1691 & 1691 & 1691 \\
\hline
\end{tabular}

Un acercamiento común a este tipo de decisiones consiste en utilizar el Criterio de Infomación de Akaike (AIC). Este criterio propone penalizar cada logaritmo de verosimilitud, de manera que refleje el número de parámetros que se están estimando en cada modelo $\mathrm{y}$, entonces, comparar los mismos. En este tipo de modelos, el valor de AIC vendrá definido por

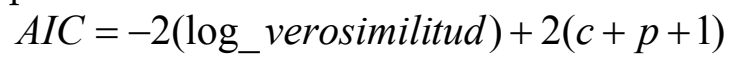

donde $c$ es el número de covariables y $p$ el número de parámetros auxiliares del modelo ( 1 en la distribución Weibull y 1 en la Gompertz).

Aunque el modelo que presenta un mejor ajuste es siempre aquél que tiene un mayor valor en su logaritmo de verosimilitud, siempre será preferible el que presente un menor valor de AIC. Por tanto, según se desprende de los resultados del Cuadro 3, la mejor estimación resulta ser

${ }_{17}$ Basta recordar que la distribución Weibull incorpora a la Exponencial como caso especial, cuando $a=1$; y que las distribuciones Weibull y Log-normal son casos específicos de distribuciones Gamma generalizadas, cuando $m=1$ y $m=0$, respectivamente 
la del modelo Gompertz con heterogeneidad Gamma, puesto que, su logaritmo de verosimilitud es el mayor de los cuatro, y su valor AIC el menor de ellos.

Otra alternativa para seleccionar el mejor modelo consiste en analizar el comportamiento de los residuos generados a través de la estimación y quedarse con aquel modelo, cuyos residuos presenten un mejor comportamiento (Kiefer, 1988). El método de análisis de residuos más sencillo consiste en la estimación de los residuos generalizados de Cox-Snell, puesto que, si el modelo ha sido especificado correctamente, estos deberían comportarse como una función exponencial unitaria.

Kiefer (1988) propone verificar el ajuste del modelo, una vez obtenidos los residuos generalizados de Cox-Snell, calculando una estimación empírica de la función integrada de riesgo, basada por ejemplo en los estimadores de Kaplan-Meier, tomando los residuos de Cox-Snell como la nueva variable de duración, pero manteniendo la misma variable indicadora de la existencia de censura. De esta manera, se podrá graficar dicha función integrada de riesgo, poniendo en el eje de abscisas los residuos. Si el modelo se ajusta bien a los datos, entonces el gráfico debería mostrar una línea con pendiente igual a uno.

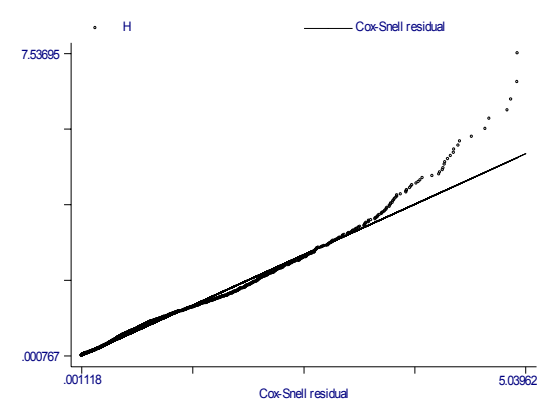

Weibull con heterogeneidad Gamma

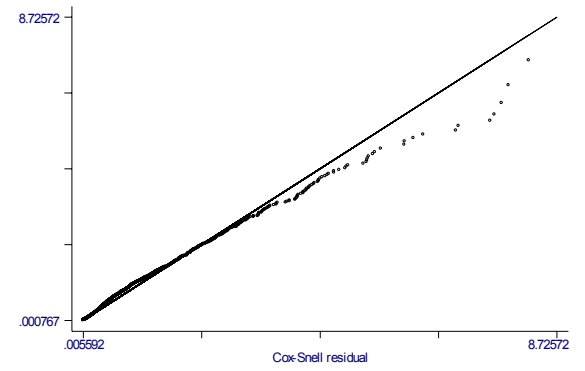

Weibull con heterogeneidad inversa
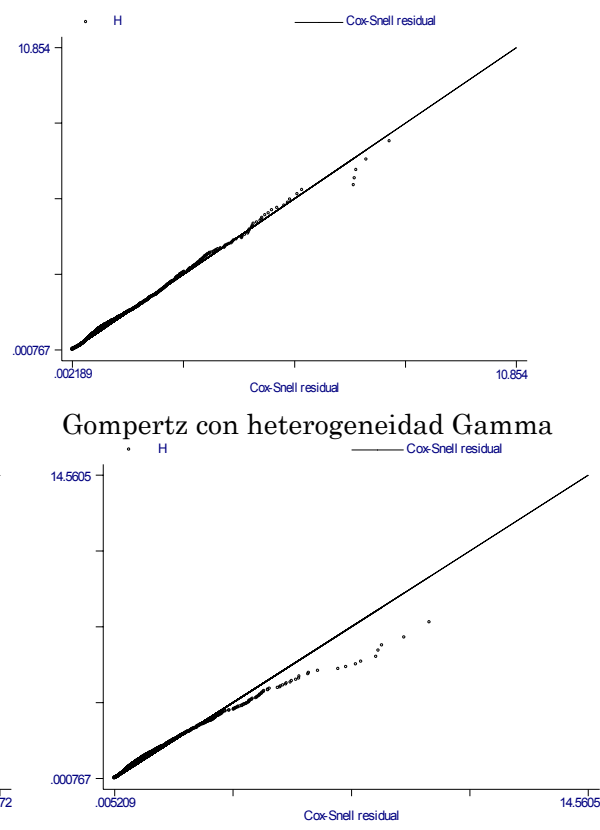

Gompertz con heterogeneidad Gaussiana inversa

Gráfico 3: Función integrada de riesgo de los residuos generalizados de Cox-Snell para la estimación de la duración del primer período de paro 
La representación gráfica de los residuos de Cox-Snell obtenidos a partir de los cuatro modelos estimados, son los que se recogen en el Gráfico 3.

Como vemos en el Gráfico 3, los residuos cuya función integrada de riesgo se asemeja más a una distribución exponencial unitaria, son los generados a través de la estimación Gompertz con heterogeneidad Gamma. Por lo que, sin duda, ésta es la estimación que mejor se ajusta a nuestros datos.

\section{Resultados}

Finalmente, en este apartado, presentaremos los resultados obtenidos en el análisis de la duración del período de paro al que se enfrentan los titulados antes de obtener su primer empleo, a través de la estimación de un modelo Gompertz que controla la existencia de heterogeneidad de tipo Gamma (Cuadro 4).

En este modelo, un coeficiente estimado positivo, indica que la variable en cuestión provoca un incremento en la tasa de riesgo de salir del desempleo hacia la ocupación y, por tanto, provoca una disminución en la permanencia del individuo en el paro.

Hemos optado por estimar el modelo diferenciando la muestra entre hombres y mujeres, aparte de realizar la estimación conjunta para toda ella, puesto que cabe esperar que la probabilidad de abandonar el desempleo difiera entre géneros y, además, que la influencia de algunas de las variables consideradas sea diferente en función del colectivo de que se trate.

Como vemos a partir de los resultados recogidos en el Cuadro 4, la heterogeneidad inobservable resulta significativa, tanto en el conjunto de la muestra, como en el colectivo de hombres y mujeres por separado, puesto que la estimación del parámetro $\sigma^{2}$ resulta estadísticamente significativa en todos los casos. Esta heterogeneidad resulta ser más acusada entre las mujeres, en cuya muestra se obtiene un mayor valor para dicho parámetro.

En lo que respecta a la influencia de las características personales y familiares, la única variable significativa para el colectivo de la muestra es la que hace referencia a la experiencia previa, mostrando un efecto positivo de la misma sobre la probabilidad de encontrar empleo ${ }^{18}$. Ello

18 Para obtener la magnitud de su influencia habría que calcular $\left(e^{\beta}-1\right) 100$, lo que nos proporcionaría el incremento porcentual que sufriría la tasa de riesgo de abandono del desempleo. 
puede ser interpretado como la recompensa, en términos de reducción del periodo de desempleo, a la acumulación de capital humano específico. Biggeri et al. (2001) detectan un efecto similar de la experiencia sobre la probabilidad de abandonar el desempleo, estimando un modelo discreto de duración multinivel, que explica la probabilidad de salida del desempleo de los titulados universitarios que finalizaron sus estudios en Italia en 1992.

Cuadro 4: Estimación del modelo de duración tipo Gompertz con heterogeneidad Gamma para el primer período de paro (por género)

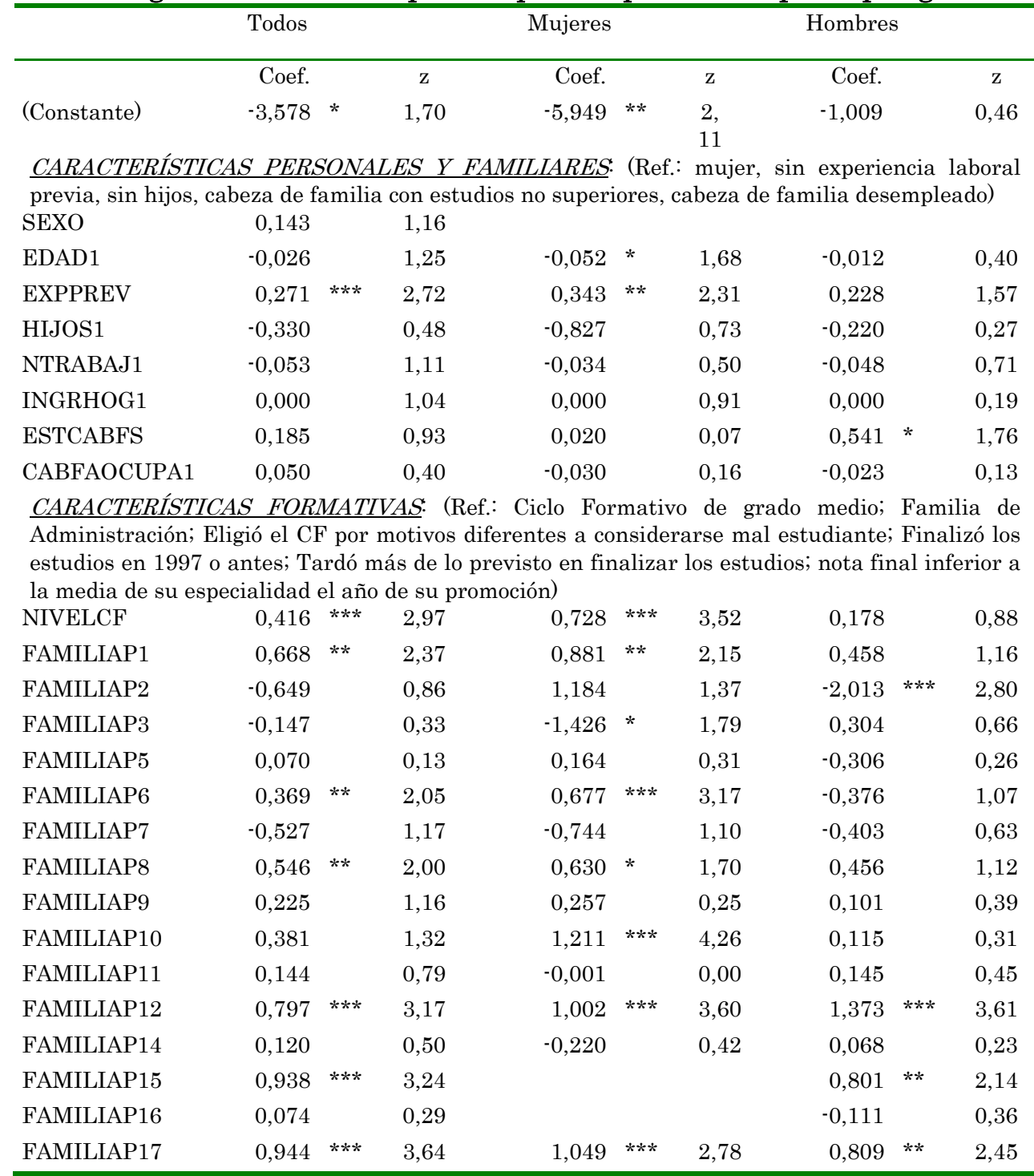




\begin{tabular}{|c|c|c|c|c|c|c|c|c|}
\hline FAMILIAP18 & 0,255 & & 0,34 & $-0,245$ & & 0,19 & 0,710 & 1,25 \\
\hline FAMILIAP19 & 0,014 & & 0,07 & 0,133 & & 0,56 & $-0,111$ & 0,27 \\
\hline FAMILIAP20 & 0,498 & $*$ & 1,88 & 0,364 & & 1,20 & $1,204 * * * *$ & 2,79 \\
\hline FAMILIAP21 & $-0,294$ & & 0,21 & $-0,158$ & & 0,12 & $-1,160$ & \\
\hline ACCDIREC & $-0,015$ & & 0,13 & $-0,065$ & & 0,35 & $-0,048$ & 0,32 \\
\hline PUB_PRI & 0,008 & & 0,03 & 0,086 & & 0,30 & $-0,364$ & 1,00 \\
\hline MALESTUD & $-0,087$ & & 0,44 & $-0,494$ & $*$ & 1,67 & 0,383 & 1,60 \\
\hline FIN98 & 0,422 & $* *$ & 1,97 & 0,376 & & 1,34 & 0,473 & 1,39 \\
\hline FIN99 & 0,514 & $* *$ & 2,14 & 0,649 & $* *$ & 2,14 & 0,188 & 0,48 \\
\hline FIN00 & 0,559 & & 0,89 & 0,067 & & 0,10 & $2,236 *$ & 1,93 \\
\hline TARDAPREV2 & 0,631 & & 1,23 & 1,020 & & 1,42 & $-0,085$ & 0,10 \\
\hline TARDAPREV3 & 0,391 & & 0,72 & 0,939 & & 1,24 & $-0,599$ & 0,68 \\
\hline NOTASUP & 0,219 & $* *$ & 2,32 & 0,350 & $* *$ & 2,53 & 0,132 & 0,99 \\
\hline \multicolumn{9}{|c|}{ VARIABLES DE ENTORNO: (Ref.: Estudió en centro de la ciudad de Las Palmas de Gran } \\
\hline RUR_URB & 0,155 & & 1,32 & 0,255 & & 1,51 & 0,071 & 0,43 \\
\hline TASADESJ & 0,072 & & 1,35 & 0,149 & $* *$ & 2,10 & -0.005 & 0,06 \\
\hline AÑOCOM_97 & & & & & & & 0,758 & 0,43 \\
\hline AÑOCOM_98 & $-0,491$ & & 0,95 & $-1,153$ & & 1,50 & 0,954 & 0,72 \\
\hline AÑOCOM_99 & $-0,415$ & & 0,64 & $-0,314$ & & 0,40 & 0,316 & 0,42 \\
\hline AÑOCOM_00 & $-0,378$ & & 0,48 & $-0,108$ & & 0,11 & 0,294 & 0,68 \\
\hline AÑOCOM_01 & $-0,318$ & & 0,34 & 0,257 & & 0,22 & & \\
\hline
\end{tabular}

CARACTERÍSTICAS DEL PROCESO DE BÚSQUEDA: (Ref.: No utilizó el envío de currículos, no se apuntó en el INEM, no acudió a una ETT, no respondió anuncios en prensa, no contactó con los encargados de la FCT, no se apuntó en bolsas de trabajo)

\begin{tabular}{|c|c|c|c|c|c|c|c|c|c|}
\hline NMEDBUS1 & $-0,534$ & $* *$ & 2,20 & $-0,864$ & $* * *$ & 3,61 & $-0,789$ & $* * *$ & 3,25 \\
\hline CURRIC1 & $-1,074$ & $* * *$ & 3,53 & $-0,790$ & $* *$ & 2,17 & $-0,808$ & $* *$ & 2,22 \\
\hline INEM1 & $-0,181$ & & 0,64 & 0,076 & & 0,21 & 0,282 & & 0,89 \\
\hline ETT1 & $-0,271$ & & 0,95 & 0,190 & & 0,59 & $-0,171$ & & 0,51 \\
\hline PRENSA1 & $-0,306$ & & 0,99 & & & & & & \\
\hline CONTACT1 & $-0,037$ & & 0,13 & 0,284 & & 0,91 & 0,254 & & 0,77 \\
\hline FCT1 & 0,930 & $* * *$ & 3,32 & 1,201 & $* * *$ & 4,14 & 1,293 & $* * *$ & 4,08 \\
\hline BOLSAST1 & 0,479 & * & 1,67 & 1,005 & $* * *$ & 2,73 & 0,580 & * & 1,78 \\
\hline OPOSIC1 & & & & 0,369 & & 0,96 & 0,133 & & 0,25 \\
\hline$\Gamma$ & 0,009 & $* * *$ & 8,55 & 0,009 & $* * *$ & 7,01 & 0,009 & $* * *$ & 4,39 \\
\hline$\Sigma^{2}$ & 1,474 & $* * *$ & 16,0 & 1,571 & $* * *$ & 11,2 & 1,202 & $* * *$ & 9,67 \\
\hline $\mathrm{Chi}^{2}$ & \multicolumn{3}{|c|}{$1004,360 \quad \mathrm{p}=0,000$} & \multicolumn{3}{|c|}{$583,320 \mathrm{p}=0,000$} & \multicolumn{3}{|c|}{$310,780 \mathrm{p}=0,000$} \\
\hline Log. Verosimilitud & \multicolumn{3}{|c|}{$-4873,841$} & \multicolumn{3}{|c|}{$-2762,602$} & \multicolumn{3}{|c|}{$-2059,541$} \\
\hline $\mathrm{N}^{\mathrm{o}}$ observaciones & \multicolumn{3}{|c|}{1691} & \multicolumn{3}{|c|}{926} & \multicolumn{3}{|c|}{765} \\
\hline
\end{tabular}

Estadísticos $z$ robustos en valor absoluto

* significativo al $10 \% ; * *$ significativo al $5 \% ; * * *$ significativo al $1 \%$

El resto de las variables incluidas en este primer bloque resultan no significativas en el conjunto de la muestra. Así, por ejemplo, el número de hijos no influye sobre la probabilidad de abandono del desempleo, al 
igual que sucedió en los estudio de Ahn y Ugidos-Olazábal (1995) y Kettunen (2002); y el nivel educativo del cabeza de familia, así como el hecho de que éste tenga o no un empleo, tampoco influye sobre dicha probabilidad, como ya sucedió en el estudio de Theeuwes (1989) sobre la población entre 15 y 26 años desempleada en los Países Bajos.

A pesar de que, en la muestra conjunta, la variable sexo no resulte estadísticamente significativa, la estimación diferenciada por género nos revela una influencia desigual de las características personales sobre la duración del período de desempleo. De hecho, así como la edad no parece tener ninguna influencia sobre la probabilidad de abandono del desempleo entre los varones, ésta presenta un efecto negativo en el caso de las mujeres, de forma que a mayor edad, menor resulta su tasa de riesgo de abandono del desempleo. Biggeri et al. (2201) y Kettunen (2002) constataron este mismo efecto de la edad, pero para el colectivo global de su muestra.

Igualmente, la influencia positiva de la experiencia laboral previa sobre la probabilidad de consecución del primer empleo detectada para el conjunto de la muestra, al estimar el modelo diferenciando por género, resulta solamente significativa en el colectivo de las mujeres. Mientras que, el pertenecer a una familia cuyo cabeza de familia posea estudios superiores, conlleva un aumento en la probabilidad de salida del desempleo únicamente entre los titulados varones. Este último resultado está en consonancia con el argumento de que las familias de los jóvenes adoptan estrategias tendentes a la inserción laboral de sus hijos (Rees y Gray, 1982; Rosenbaum, DeLuca, Miller y Roy, 1999). Estas estrategias estarán condicionadas, según estos mismos autores, por los contactos, influencias y redes profesionales de los padres. En nuestro estudio, el nivel educativo del cabeza de familia está actuando como proxy de la clase social.

En lo que respecta a las características formativas de los titulados observamos que la duración del período de paro disminuye por haber cursado un Ciclo Formativo Superior. Este resultado, congruente con la teoría del capital humano, es consistente, asimismo, con la estimación no paramétrica realizada previamente (ver Gráfico 2), en donde veíamos que la función de supervivencia de los técnicos se mantenía continuamente por encima de la de los técnicos superiores. De la misma manera, este resultado es consistente con los resultados de los estudios de Theeuwes (1989), Ahn y Ugidos-Olazábal (1995), Bratberg y Nilsen (2000) y Congregado-Ramírez y García-Pérez (2002), quienes observan que los individuos con mayor nivel educativo salen antes del desempleo que los de menor nivel formativo.

Diferenciando por sexo, sin embargo, vemos que este efecto no es significativo en el caso de los hombres, aunque sí lo es en el de las mujeres. 
El primer periodo desempleo de técnicos y técnicos superiores

Ahn y Ugidos-Olazábal (1995), en su estudio a partir de la Encuesta de Condiciones de Vida y Trabajo de 1985, detectan que la influencia de la educación era más pronunciada entre mujeres que entre hombres, aunque para estos últimos seguía siendo significativa. Sin embargo, Petrongolo (2001), al igual que en nuestro estudio, encuentra una influencia positiva del nivel educativo únicamente entre las mujeres.

Tomando como referencia las titulaciones de la Familia Profesional de 'Administración', observamos que la duración del período de desempleo disminuye en el caso de haber cursado algún Ciclo Formativo de las Familias de 'Actividades Agrarias', 'Comercio y Marketing', 'Edificación y Obra Civil', 'Imagen Personal', 'Madera y Mueble', 'Mantenimiento y Servicios a la Producción' o 'Servicios Socioculturales y a la Comunidad'; siendo los titulados de 'Mantenimiento y Servicios a la Producción' los que presentan una mayor probabilidad de consecución del primer empleo, al igual que se detectó mediante la estimación no paramétrica. Diferenciando por género, observamos que, curiosamente, la titulación que presenta una menor duración del desempleo entre las mujeres, es la de 'Fabricación Mecánica', mientras que, entre los hombres, es la de 'Imagen Personal'. Estos resultados son fiel reflejo de la demanda que de cada una de las Familias Profesionales hace el mercado.

El acceder a los estudios de Formación Profesional Específica a través de una ruta estructurada, la titularidad del centro de estudios o el tiempo que tarden los titulados en finalizar el Ciclo Formativo, según nuestras estimaciones, no influyen en la duración del período de desempleo, de donde se podría deducir que los empleadores no tienen en cuenta estos aspectos a la hora de ofertar un trabajo.

Sin embargo, el año en el que los titulados finalicen sus estudios sí que influye sobre la duración del período de desempleo. De hecho, para el colectivo global de la muestra, se observa que las cohortes más recientes de titulados presentan una menor duración de su período de desempleo, lo que nos vuelve a presentar indicios de la mayor apreciación de la Formación Profesional en el mercado de trabajo y del efecto cicloeconómico sobre la demanda de este tipo de titulaciones. Hay múltiples trabajos en España que encuentran un efecto significativo del ciclo económico sobre la duración del periodo de desempleo (Bover et al., 2002; Alba-Ramírez, 1998). No obstante, la teoría de búsqueda de empleo no proporciona predicciones (en signo) del efecto del ciclo económico sobre la probabilidad de abandono de la situación de desempleo.

Por último, en cuanto a las características formativas de los titulados, observamos, cómo las mujeres que han optado por realizar un Ciclo Formativo por considerarse malas estudiantes, presentan una menor probabilidad de abandonar el desempleo, lo que podría ser debido, entre otras razones, a una posible falta de autoestima de estas tituladas o a que, 
sencillamente, estas personas carecen de las habilidades demandadas por el mercado de trabajo para ocupar un empleo. Y, finalmente, observamos que, la nota media obtenida en el Ciclo Formativo sólo influye en la duración del desempleo entre las mujeres, al igual que sucedía en el estudio de Biggeri et al. (2001). De manera que, aquellas tituladas que presentan una nota media superior a la de su cohorte en su especialidad, tendrán una mayor probabilidad de abandonar el desempleo que las que tienen una nota media inferior. El razonamiento subyacente es la existencia de un capital humano 'potencialmente mayor' de estos titulados con mejores expedientes, lo que supone una señal positiva sobre la productividad esperada del individuo por parte del empresario demandante.

En cuanto a la influencia que ejercen las características del entorno económico, no se aprecia efecto alguno en el conjunto de la muestra, ni en el colectivo de los hombres. Entre las mujeres, sin embargo, resulta llamativo que la tasa de desempleo juvenil canario tenga un efecto positivo, y tan acusado, sobre la tasa de riesgo de salida del desempleo de éstas. Esto es debido probablemente a que, en periodos de altas tasas de desempleo, las mujeres, conocedoras de sus menores oportunidades de ser contratadas, reducen sus salarios de reserva, lo que incrementa su probabilidad de abandonar el desempleo. Este efecto se ve incrementado, además, por el temor a la pérdida de capacidad productiva debido a la merma del capital humano de estos individuos con titulación específica.

Finalmente, en lo que respecta a las características del proceso de búsqueda, observamos que, cuantos más medios de búsqueda diferentes utiliza el titulado, menor resulta su tasa de riesgo de salida, es decir, mayor su permanencia en el desempleo. Es posible que este fenómeno responda a que, los titulados que se consideran con menos probabilidades de conseguir empleo, utilicen el mayor número posible de medios a su alcance para lograr su primer empleo. Mientras que, por el lado contrario, aquellos titulados que se consideran más 'capaces' utilizan un menor número de medios, pero que les resultan más efectivos. Se comprueba aquí, al igual que en otros estudios (Moltó et al, 1994) cómo lo más frecuente es el proceso de búsqueda sistemático, en lugar del aleatorio.

Entrando en el análisis de la efectividad de los medios de búsqueda, observamos que, el envío de currículos, curiosamente, parece reducir la tasa de riesgo de salida, mientras que, el acudir a los responsables de la FCT y el apuntarse a las bolsas de trabajo, reduce considerablemente la duración del período de desempleo. El resto de los medios de búsqueda utilizados por los titulados, resultan no ser estadísticamente significativos. No existe consenso en la literatura empírica acerca de la eficacia de los diferentes medios de búsqueda de empleo. 
Por último, observamos que el valor estimado del parámetro auxiliar del modelo de duración tipo Gompertz, $Y$, resulta significativo y toma un valor positivo ${ }^{19}$. Este valor nos indica una dependencia temporal de la duración del desempleo positiva. Es decir, que la función de riesgo y, por tanto, la probabilidad condicionada de abandonar el desempleo, aumenta ligeramente con la duración del episodio de paro.

A la luz de este resultado podemos concluir que, aunque al prolongarse la búsqueda, la tasa de llegada de ofertas laborales pueda disminuir, por considerar los empleadores que esto es una señal de la baja productividad de los individuos y, en consecuencia, del deterioro de su capital humano, el efecto en la probabilidad de aceptación de los individuos, como consecuencia del deterioro de su nivel de exigencia y de la disminución de su salario de reserva, llega a compensar dicha disminución, con lo que, el efecto final resulta ser positivo y la probabilidad de abandonar el desempleo aumenta con su duración.

Por tanto, la estimación señala hacia una función de supervivencia que va disminuyendo hacia una asíntota que toma el valor cero, implicando así que, a largo plazo, prácticamente todos los titulados conseguirían su primer empleo. No obstante, el hecho de que el valor estimado de $\gamma$ resulte tan cercano al cero, nos indica que la relación de dependencia positiva entre la función de riesgo y el tiempo es débil y, por tanto, el crecimiento de dicha función será moderado (ver Gráfico 1).

\section{Conclusiones}

A través del análisis no paramétrico de la duración del primer período de desempleo de los titulados en Formación Profesional, se comprueba la existencia de divergencias en función del género, del nivel del CF y de la Familia Profesional. De hecho, observamos que, a pesar de que tanto hombres como mujeres presentan una alta probabilidad de salida del desempleo en un período inferior a una semana, ésta es 5 puntos superior entre los hombres que entre las mujeres. De la misma forma, observamos que los técnicos superiores presentan una menor duración del desempleo que los técnicos en períodos inferiores al año. Y, por último, observamos que la Familia Profesional que se enfrenta a peores oportunidades laborales en el mercado de trabajo, parece ser la de 'Textil, Confección y Piel', mientras que la que se enfrenta a las mejores oportunidades laborales resulta ser la de 'Mantenimiento y Servicios a la

${ }_{19} \mathrm{Al}$ estimar el modelo sin la corrección de heterogeneidad inobservable, el valor estimado de $Y$ muestra una relación de dependencia negativa, aunque toma un valor muy cercano a cero (-0.003). 
Producción'.

No obstante, el análisis de los datos de duración nos presenta evidencias de que la transición hacia el primer empleo es un fenómeno complejo en el que intervienen muchos y diversos factores. De hecho, mediante la estimación diferenciada por género de un modelo Gompertz con heterogeneidad Gamma, entre otras cosas, observamos que, para los hombres resulta favorable tener un cabeza de familia con estudios superiores, haber cursado un CF de la rama de 'Imagen Personal', haber acudido a los responsables de la FCT o apuntarse en bolsas de trabajo, pues estos factores provocan una disminución en su duración de desempleo. En cambio, entre las mujeres, lo que consigue disminuir la duración de su desempleo es el tener experiencia laboral previa al CF, el cursar un Ciclo Superior o la rama de 'Fabricación Mecánica', tener una nota final superior a la media de su promoción y especialidad y, al igual que los hombres, acudir a los responsables de la FCT y apuntarse a bolsas de trabajo.

Por otro lado, si los hombres optan por utilizar muchos medios de búsqueda diferentes y, sobre todo, por utilizar como medio de búsqueda el envío de currículos, su período de desempleo se verá incrementado. Este patrón se repetirá en el caso de las mujeres, aunque éstas también sufrirán un mayor período de desempleo en caso de haber optado por el CF por considerarse malas estudiantes a la vez que experimentarán una relación positiva entre la edad y la duración de su período de desempleo.

\section{Bibliografía}

Aguilar, M.I. (2001): "La inserción laboral de los jóvenes en España. Un enfoque microeconométrico", Tesis Doctoral, Universidad de Málaga.

Ahn, N. y Ugidos, A. (1995): "Duration of unemployment in Spain: Relative effects of unemployment benefit and family characteristics", Oxford Bulletin of Economics and Statistics, vol. 57 (2), 249-264

Alba-Ramírez, A. (1998): "Re-employment probabilities of young workers in Spain”, Investigaciones Económicas, vol. 22 (2), 201-224

Alba-Ramírez, A. y Álvarez, G. (2004): "La actividad laboral de la mujer en el entorno del nacimiento de un hijo", Investigaciones Económicas, vol. 28 (en prensa)

Alujas, J.A. (2003): Políticas Activas de Mercado de Trabajo en España, CES, Colección Estudios, Madrid. 
El primer periodo desempleo de técnicos y técnicos superiores

Biggeri, L., Bini, M. y Grilli, L. (2001): "The transition from university to work: A multilevel approach to the analysis of the time to obtain the first job", Journal of the Royal Statistical Society - Series A, vol. 164 (2), 293305

Bover, O.; Arrellano, M. y S. Bentolila (2002): "Unemployment Duration, Benefit Duration, and the Business Cycle", Economic Journal, vol. 112 (479), 223-265.

Bover, O. y Gómez, R. (2004): "Another look at unemployment duration: long-term unemployment and exit to a permanent job", Investigaciones Económicas, vol. 28, (en prensa)

Bowers, N., Sonnet, A. y Bardone, L. (1999): "Giving Young People a Good Start: The Experience of OECD Countries", en OECD, Preparing youth for the 21st century: The transition from education to the labour market. OECD, Paris, 7-86

Bratberg, E. y Nilsen, O.A. (2000): "Transitions from school to work and the early labour market experience". Oxford Bulletin of Economics and Statistics, vol. 62, special issue, 909-929

Comisión Europea (1990): El Empleo en Europa. Luxemburgo

Congregado, E. y García, J.I. (2002): "El problema del desempleo en la economía andaluza (1990-2001): Análisis de la transición desde la educación al mercado laboral", Fundación centro de estudios andaluces (centrA), Documento de trabajo, Serie Economía E2002/17

D'Agostino, A. y Mealli, F. (2000): "Modelling short unemployment in Europe", Working Paper 2000-06, Institute for Social and Economic Research (ISER), University of Essex

Devine, T.J. y Kiefer, N.M. (1991): Empirical labor economics: The search approach, Oxford University Press, New York

Devine, T.J. y Kiefer, N.M. (1993): "The empirical status of job search theory”, Labour Economics, vol. 1 (1), 3-24

Eckstein, Z. y Van Den Berg, G.J. (2001): "Métodos empíricos para el estudio de los mercados de trabajo con fricciones de búsqueda. Un resumen de la literatura”, Cuadernos Económicos de ICE, 66, 9-19.

Gámez, C. y García, J.I. (2002): "Flujos de trabajadores en el mercado de trabajo andaluz", Fundación centro de estudios andaluces (centrA), Documento de trabajo, Serie Economía E2002/02 
Gil, J.A. (1998): Inserción Laboral y desajuste educativo de los titulados universitarios. Un estudio de los titulados de la ULPGC (1988-1996). Universidad de Las Palmas de Gran Canaria.

González-Betancor, S.M. (2003): "Inserción laboral, desajuste educativo y trayectorias laborales de los titulados en Formación Profesional específica en la isla de Gran Canaria (1997-2000)", Tesis Doctoral, Universidad de Las Palmas de Gran Canaria

Gutiérrez-Domenech, M. (2002): "The impact of the labour market on the timing of marriage and births in Spain", CEP Discussion Paper $\mathrm{n}^{\circ} 0556$, Centre for Economic Performance (CEP)

Han, A. y Hausman, J.A. (1990): "Flexible parametric estimation of duration and competing risk models", Journal of Applied Econometrics, vol. 5 (1), 1-28

Holzer, H.J. (1988): "Search methods used by unemployed youth", Journal of Labor Economics, vol. 6 (1), 1-20

Kaplan, E.L. y Meier, P. (1958): "Nonparametric estimation for incomplete observations", Journal of the American Statistical Association, vol. 53, 457-481

Kettunen, J. (2002): "Labour mobility of unemployed workers", Regional Science and Urban Economics, vol. 32 (3), 359-380

Kiefer, N.M. (1988): "Economic Duration Data and Hazard Functions", Journal of Economic Literature, vol. 26 (2), 646-679

Klein, J.P. y Moeschberger, M.L. (1997) : Statistics for Biology and Health, Springer-Verlag, New York

Lancaster, T. (1992): The Econometric Analysis of Transition Data. Cambridge University Press, New York

Lázaro, N., Moltó, M.L. y Sánchez, R. (2000): "Unemployment determinants for women in Spain”, Labour, vol. 14 (1), 57-78

Mantel, N. y Haenszel, W. (1959): "Statistical aspects of the analysis of data from retrospective studies of disease", Journal of the National Cancer Institute, vol. 22, 719-748

Melkersson, M. (1999): "Unemployment duration and heterogenous search behavior among Swedish disabled workers”. Institute for Labour Market 
Policy Evaluation (IFAU) Working Paper Series, 1999:5

Moltó, M., Peraita, C., Sánchez, M. y Uriel, E. (1994): "Elección de métodos e intensidad de búsqueda de empleo en los desempleados", Revista de Economía Aplicada, vol. 2 (4), 53-74

Mortensen, D.T. (1986): "Job search and labor market analysis", en Ashenfelter, O.C. y Card, D. (eds.): Handbook of Labour Economics, Volume 2, Elservier Science, North-Holland, 849-919

Nickell, S.J. (1979): "Estimating the probability of leaving unemployment", Econometrica, vol. 47 (5), 1249-1266

OCDE (2002): Perspectivas del Empleo 2002. Ministerio de Trabajo y Asuntos Sociales, Subdirección General de Publicaciones, Madrid.

Petrongolo, B. (2001): "Re-employment probabilities and returns to matching", Journal of Labor Economics, vol. 19, 716-741

Rees, A. y Gray, W. (1982): "Family effects in youth employment" en Freeman, R.B. y Wise, D.A. (eds.): The Youth Labor Market Problem: Its Nature, Causes and Consequences, Chicago University Press, 453-464

Rivas, M.J. y López, J. (2000): Análisis de Supervivencia. Editorial la Muralla. Madrid.

Rosenbaum, J.E., DeLuca, S., Miller, S.R. y Roy, K. (1999): "Pathways into work: Short-and long-term effects of personal and institutional ties", Sociology of Education, vol. 73 (3), 179-196

Salas, M. (2000): "Inversión en capital humano: Demanda, búsqueda de empleo y rendimientos privados de la educación superior. Una aproximación metodológica al estudio del mercado de trabajo de los titulados", Tesis Doctoral. Universidad de Granada.

Stancanelli, E. (1998): "Unemployment compensation schemes and unemployment duration", Applied Economics Letters, vol. 5 (11), 675-680

Stata-Corp. (2001): Stata Statistical Software: Release 7.0, College Station, TX: Stata Corporation

Theeuwes, J. (1989): "Unemployment and Labour Market Transition Probabilities", en Muysken, J. y De Neubourg, C. (eds.) Unemployment in Europe, Macmillan, 37-55 


\section{Anexo A.1.}

El contraste de 'Cox' es un contraste de igualdad de funciones de distribución que se suele utilizar cuando se trabaja con bases de datos ponderadas, puesto que, en ese caso, el contraste log-rank propuesto por Mantel y Haenszel (1959) resultaría inapropiado (StataCorp., 2001).

A continuación mostramos cómo se lleva a cabo dicho contraste de una manera genérica, con el fin de poder interpretar correctamente los resultados que se presentan en el artículo.

Sean $t_{1}<t_{2}<\ldots<t_{k}$ las diferentes duraciones observadas en la muestra. Llamemos $d_{j}$ al número de observaciones que finalizan tras una duración $t_{j}$ y $n_{j}$ al conjunto de riesgo justo antes del momento $t_{j}$. Añadiendo el subíndice $i$ hacemos referencia a cada uno de los diferentes grupos, siendo $i=1,2, \ldots, r$.

La hipótesis nula a contrastar es la siguiente:

$$
H_{0}: h_{1}(t)=h_{2}(t)=\ldots=h_{r}(t)
$$

Donde $h(t)$ es la función de riesgo en el momento $t$, frente a una hipótesis alternativa que sugiera que al menos una de las $h_{i}(t)$ es diferente en algún $t_{j}$.

En caso de que la hipótesis nula fuera cierta, el número esperado de finalizaciones del grupo $i$ en el momento $t_{j}$ sería $\hat{d}_{i j}=n_{i j} d_{j} / n_{j}$, obteniendo el siguiente estadístico de contraste:

$$
u^{\prime}=\sum_{j=1}^{r} W\left(t_{j}\right)\left(d_{1 j}-\hat{d}_{1 j}, \ldots, d_{r j}-\hat{d}_{r j}\right)
$$

Donde $W\left(t_{j}\right)$ es una función de ponderación positiva que toma el valor cero cuando $n_{i j}$ vale cero.

Este estadístico, que es genérico para cualquier contraste de homogeneidad, tomará diferentes especificaciones dependiendo de la función de ponderación elegida. Así, en el caso concreto del log-rank test de Mantel y Haenzel, se asigna un peso igual a la unidad para cada momento de finalización $t_{j}$, pues se supone que la función de riesgo, si no es igual, es proporcional entre los diferentes grupos, por lo que la contribución de cada duración sobre el conjunto del estadístico debe ser la misma.

La matriz de varianzas covarianzas $V$ para el estadístico $u$ está compuesta por los elementos

$$
V_{i l}=\sum_{j=1}^{r} \frac{W\left(t_{j}\right)^{2} n_{i j} d_{j}\left(n_{j}-d_{j}\right)}{n_{j}\left(n_{j}-1\right)}\left(\omega_{i l}-\frac{n_{i j}}{n_{j}}\right)
$$

donde $\omega_{i l}=1$ si $i=l$ y $\omega_{i l}=0$ en otro caso.

En caso de tener una muestra no estratificada, el estadístico $u^{\prime} V^{-1} u$ 
se distribuye como una $\chi^{2}$ con $r-1$ grados de libertad.

El contraste de 'Cox' se realiza estimando un modelo de riesgo proporcional de Cox con $r-1$ variables índice. Cada una de estas variables hace referencia a cada uno de los diferentes grupos, quedando uno de ellos omitido como referencia. El valor del contraste $\chi^{2}$ se corresponde entonces con el valor del contraste de Wald o con el del contraste de razón de verosimilitudes.

Se trata, por tanto, de comparar la probabilidad de supervivencia empírica con la estimada. Para ello se calcula para cada intervalo, tomando en consideración el global de la muestra, el número de individuos $n_{j}$ que conforman el conjunto de riesgo y el número de observaciones $d_{j}$ que finalizan tras una duración $t_{j}$. Para r-grupos, se calculará para cada intervalo:

$$
n_{j T}=n_{j 1}+n_{j 2}+\ldots+n_{j r} \quad \text { y } \quad d_{j T}=d_{j 1}+d_{j 2}+\ldots+d_{j r}
$$

A continuación, para cada grupo, en cada intervalo, se calcula el número de finalizaciones predichas

$$
\hat{d}_{j r}=d_{j T} \times \frac{n_{j r}}{n_{j T}}
$$

donde $r$ identifica al grupo en cuestión.

Finalmente, sumando los valores predichos y observados para cada grupo se puede calcular el estadístico $\chi^{2}$

$$
\begin{array}{ll}
\Sigma d_{1}=\sum d_{j 1} & \text { (la suma de todas las } d_{j} \text { del grupo 1) } \\
\Sigma \hat{d}_{1}=\sum \hat{d}_{j 1} & \text { (la suma de todas las } \hat{d}_{j} \text { del grupo 1) }
\end{array}
$$

etc.

$$
\chi^{2}=\frac{\left(\sum d_{1}-\sum \hat{d}_{1}\right)^{2}}{\sum \hat{d}_{1}}+\frac{\left(\sum d_{2}-\sum \hat{d}_{2}\right)^{2}}{\sum \hat{d}_{2}}+\ldots+\frac{\left(\sum d_{r}-\sum \hat{d}_{r}\right)^{2}}{\sum \hat{d}_{r}} \sim \chi_{r-1}^{2}
$$

En la realización del contraste de 'Cox' se obtiene un valor del riesgo relativo para cada uno de los grupos. Éste no es más que la exponencial del coeficiente de una regresión de Cox re-normalizada, aunque dicha re-normalización no juega ningún papel en el cálculo del estadístico de contraste, puesto que ésta se elige de forma tal que la media ponderada de los coeficientes de regresión para el número esperado de finalizaciones de cada grupo valga cero, lo que equivale a decir que el riesgo valga uno.

Por tanto, sean $b$, con $i=1,2, \ldots, r-1$, los coeficientes estimados y sea $b_{r}=0$. La constante $K$ se calcula como 


$$
K=\sum_{i=1}^{r} \frac{\hat{d}_{i} b_{i}}{d}
$$

donde $\hat{d}_{i}=\sum_{j} \hat{d}_{i j}$ es el número esperado de finalizaciones para el grupo $i$, $d$ es el número total de finalizaciones entre todos los grupos y $r$ el número de grupos. Así, el riesgo relativo se calculará, finalmente, como $e^{\left(b_{i}-K\right)}$.

\section{Anexo A.2.}

Las variables independientes que hemos utilizado en la estimación del modelo de duración son las que definimos a continuación.

Características personales y familiares

SEXO: variable dicotómica que toma valor 1 si el titulado es hombre EDAD1: edad del titulado al comenzar a trabajar en su primer empleo EXPPREV: variable dicotómica que toma valor 1 si el titulado reconoce haber tenido algún empleo previo a la finalización del CF

HIJOS1: variable dicotómica que toma valor 1 si el titulado tenía hijos al finalizar sus estudios

NTRABAJ1: número de miembros de la familia que estaban trabajando cuando el titulado finalizó sus estudios

INGRHOG1: ingresos del hogar, mientras el titulado realizaba en Ciclo Formativo, en Euros constantes de 2001

ESTCABFS: variable dicotómica que toma valor 1, cuando el cabeza de familia posee estudios superiores, y el valor 0 , en otro caso

CABFAOCUPA1: variable dicotómica que toma valor 1 , si el cabeza de familia trabajaba cuando el titulado finalizó sus estudios, y el valor 0, en otro caso

\section{Características educativas}

NIVELCF: variable dicotómica que toma el valor 1, si el titulado cursó un Ciclo Formativo de Grado Superior, y el valor 0, en caso de haber cursado uno de Grado Medio.

FAMILIAP: recoge un conjunto de variables dicotómicas que hacen referencia a la Familia Profesional a la que pertenece el Ciclo Formativo cursado por el titulado. En el caso de FAMILIAP1 el CF pertenece a la Familia de Actividades Agrarias; en FAMILIAP2 el CF pertenece a la Familia de Actividades Físicas y Deportivas; en FAMILIAP3 el CF pertenece a la Familia de Actividades Marítimo Pesqueras; en FAMILIAP5 el CF pertenece a la Familia de Artes Gráficas; en FAMILIAP6 el CF pertenece a la Familia de Comercio y Marketing; en FAMILIAP7 el CF pertenece a la Familia de Comunicación, Imagen y Sonido; en FAMILIAP8 el CF pertenece a la Familia de Edificación y Obra 
El primer periodo desempleo de técnicos y técnicos superiores

Civil; en FAMILIAP9 el CF pertenece a la Familia de Electricidad y Electrónica; en FAMILIAP10 el CF pertenece a la Familia de Fabricación Mecánica; en FAMILIAP11 el CF pertenece a la Familia de Hostelería y Turismo; en FAMILIAP12 el CF pertenece a la Familia de Imagen Personal; en FAMILIAP13 el CF pertenece a la Familia de Industrias Alimentarias; en FAMILIAP14 el CF pertenece a la Familia de Informática; en FAMILIAP15 el CF pertenece a la Familia de Madera y Mueble; en FAMILIAP16 el CF pertenece a la Familia de Mantenimiento de Vehículos Autopropulsados; en FAMILIAP17 el CF pertenece a la Familia de Mantenimiento y Servicios a la Producción; en FAMILIAP18 el CF pertenece a la Familia de Química; en FAMILIAP19 el CF pertenece a la Familia de Sanidad; en FAMILIAP20 el CF pertenece a la Familia de Servicios Socioculturales y a la Comunidad; y, finalmente, FAMILIAP21, que indica si el CF pertenece a la Familia de Textil, Confección y Piel. Hemos dejado como referencia los Ciclos Formativos pertenecientes a la Familia de Administración.

ACCDIREC: variable dicotómica que toma valor 1 cuando el titulado reconoce haber accedido al Ciclo Formativo a través de lo que hemos llamado una 'vía estructurada', es decir, cuando accedió a un CF2 ${ }^{20}$ tras la ESO, o a un $\mathrm{CF}^{20}$ tras el Bachillerato o un CF2 de la misma Familia Profesional.

PUB_PRI: variable dicotómica que toma valor 1, si el titulado cursó el Ciclo Formativo en un centro público, y toma el valor 0, en caso contrario.

MALESTUD: variable dicotómica que toma valor 1 cuando el titulado reconoce haber optado por cursar un Ciclo Formativo por considerarse mal estudiante

FIN: recoge un conjunto de variables dicotómicas que hacen referencia al año de finalización del Ciclo Formativo. FIN98 indica que el titulado finalizó el CF en el año 1998; FIN 99 indica que lo finalizó en el año 1999; FIN00 indica que lo finalizó en el año 2000 o posteriormente. La categoría de referencia, en este caso, se refiere a los que finalizaron el CF en el año 1997 o antes.

TARDAPREV: recoge un conjunto de variables dicotómicas que hacen referencia al tiempo que tardan los titulados en finalizar su titulación. TARDAPREV2 toma el valor 1 cuando el titulado ha tardado el tiempo previsto, mientras que TARDAPREV3 toma el valor 1 cuando ha tardado menos de lo previsto. La categoría de referencia la constituyen los titulados que han tardado más de lo previsto en finalizar sus estudios.

NOTASUP: variable dicotómica que toma valor 1, cuando el titulado finaliza el $\mathrm{CF}$ con una nota media superior a la de su especialidad en el año de finalización, y toma el valor 0 , en caso contrario.

${ }^{20}$ Ciclo Formativo de Grado Medio (CF2); Ciclo Formativo de Grado Superior (CF3) 
Variables de entorno

RUR_URB: variable dicotómica que toma el valor 1, cuando el titulado cursó el CF en un centro de estudios de fuera de la capital, y toma el valor 0 si los cursó en la ciudad de Las Palmas de Gran Canaria

TASADESJ: tasa de desempleo juvenil en Canarias en la fecha en la que el titulado consiguió su primer empleo

AÑOCOM_: recoge un conjunto de variables dicotómicas que hacen referencia al año en el que los titulados consiguen su primer empleo. AÑOCOM_98 toma el valor 1 cuando el titulado consigue su empleo en el año 1998; AÑOCOM_99 toma el valor 1 cuando lo consiguen en el año 1999; AÑOCOM_00 toma el valor 1 cuando lo consigue en el año 2000; y, finalmente, AÑOCOM_01 toma el valor 1 cuando lo consiguen en el año 2001. Se deja como referencia a los que aún no han conseguido su primer empleo.

Características del proceso de búsqueda

NMEDBUS1: recoge el número de medios de búsqueda diferentes utilizados por el titulado

CURRIC1: variable dicotómica que toma el valor 1, cuando el titulado ha utilizado el envío de currículo como medio de búsqueda de su primer empleo

INEM1: variable dicotómica que toma el valor 1, cuando el titulado se ha registrado en el INEM o la ACE (Agencia Canaria de Empleo)

ETT1: variable dicotómica que toma el valor 1, cuando el titulado ha recurrido a los servicios de una Agencia de Trabajo Temporal para buscar su primer empleo

PRENSA1: variable dicotómica que toma el valor 1, cuando el titulado ha respondido a anuncios en prensa como medio de búsqueda de su primer empleo

CONTACT1: variable dicotómica que toma el valor 1, cuando el titulado ha acudido a contactos personales como medio de búsqueda de su primer empleo

FCT1: variable dicotómica que toma el valor 1, cuando el titulado ha acudido a los responsables de la formación en centros de trabajo (FCT) como medio de búsqueda de su primer empleo

BOLSAST1: variable dicotómica que toma el valor 1, cuando el titulado se ha apuntado en alguna bolsa de trabajo para conseguir su primer empleo OPOSIC1: Variable dicotómica que toma el valor 1 cuando el titulado se ha preparado unas oposiciones para conseguir su primer empleo 